\title{
Hydrologic soil group based curve number matrix modeling for Enset-Based land use system in Meki River Watershed, Western Lake Ziway Sub-Basin, Central Rift Valley of Ethiopia
}

Alemu Beyene Woldesenbet ( $\square$ alemu.beyene@aau.edu.et )

Addis Ababa University

Sebsebe Demisew Wudmatas

Addis Ababa University

Mekuria Argaw Denboba

Addis Ababa University

Azage Gebreyohannes Gebremariam

Addis Ababa University

Research

Keywords: Enset, CN, SCS, Infiltration, Carbon stock, HSG, HEC-HMS

Posted Date: January 5th, 2021

DOl: https://doi.org/10.21203/rs.3.rs-136585/v1

License: (c) (1) This work is licensed under a Creative Commons Attribution 4.0 International License.

Read Full License 
1 Hydrologic soil group based curve number matrix modeling for Enset-Based land

\section{Rift Valley of Ethiopia}

$4 \quad$ Alemu Beyene Woldesenbet ${ }^{1}$, Sebsebe Demisew Wudmatas ${ }^{2}$, Mekuria Argaw Denboba ${ }^{3}$, Azage Gebreyohannes Gebremariam ${ }^{4}$

1. Departments of Water Resources Engineering and Management, Ethiopian Institute of Water Resources, Addis Ababa University, Ethiopia and Departments of Hydraulic and Water resources Engineering, Wolkite University, Ethiopia (The corresponding author) (alemu.beyene@aau.edu.et; Mob. 0911921985)

2. Departments of Plant Biology and Biodiversity Management, College of Natural and Computational Sciences, Addis Ababa University, Ethiopia Ababa University, Ethiopia

4. Departments of Water Resources Engineering and Management, Ethiopian Institute of Water

17 "Alemu Beyene, Sebsebe Demisew, Mekuria Argaw, Azage Gebreyohannes (2020). Hydrologic soil group based curve number 18 matrix modeling for Enset-Based land use system in Meki River Watershed, Western Lake Ziway Sub-Basin, Central Rift Valley of 


\section{Background}

23 Enset-Based land use system (EBLUS) exhibits good carbon stock and infiltration rate equivalent

24 to forest covered areas, which enhances infiltration and water holding capacity and it can

25 reduce the curve number $(\mathrm{CN})$ of the watersheds but it was not considered in former studies.

26 Therefore, this study is planned to model the hydrologic soil group (HSG) based CN matrix of

27 EBLUS relative to other LUSs with established hydrological characteristics in the Meki river

28 watershed. The soil data is used to determine the HSG of the watershed collected from Ministry

29 of Water, Irrigation and Energy (MOWIE) and verified by Harmonized World Soil Database

30 (HWSD). A Model is developed for CN of EBLUS relative to other LUSs (Alemu's formula). The

31 model considers both infiltration rate measured using Amozi-meter and carbon stoke of soil

32 weighed as $85 \%$ and $15 \%$ respectively. HEC-GEO-HMS model is used to consider the CN of EBLUS

33 as a separate LUS to verify the developed CN matrix model to generate CN of the sub-

34 watersheds.

\section{Result}

36 The field measurement results show that an infiltration rate of $12.9675,11.1875,10.375,7.065$

37 and $12.8125 \mathrm{~mm} \mathrm{hr}^{-1}$ for Natural Forest, Grassland and plantation, cultivated, built-up and

38 EBLUS respectively. The model is: $\mathrm{E}=\frac{0.85 * \sum_{i=1}^{n} E I i+0.15 * \sum_{i=1}^{n} E C s i}{n}$ and the resulting CN matrix of

39 EBLUS is $39,51.5,58.3$ and 61.6 for HSG of $A, B, C$ and $D$ respectively. 


\section{Conclusion}

41 Significant reduction in mean CN of the watershed that shows the role of EBLUS in managing 42 the water resources and flood is high. Therefore, escalating EBLUS will reduce the CN of the

43 watershed which reduces runoff volume in the watershed and it ensures the sustainability of

$44 \quad$ Lake Ziway by reducing sedimentation.

45 Key words: Enset, CN, SCS, Infiltration, Carbon stock, HSG, HEC-HMS

46 
48 Land use and land cover (LULC) changes affect the processes that provide redistribution of soil

49 material and soil properties (Jerzy, Anna, \& Jan, 2014) and it leads to change in soil organic

50 carbon (SOC) and soil quality (Nyssen, Habtamu, Mulugeta, Amanuel, Nigussie, \& Mitiku, 2008).

51 Soil infiltration capacities are spatially and temporally dynamic properties due to varying land

52 use management practices (Oliver, Niels, Hogler, \& Reinhard, 2006).

53 Land cover affects the infiltration capacity of the soil (A., B., \& J., 2011; Schilling, Jha, Zhang,

54 Gassman, \& Wolter, 2008; Mao \& Cherkauer, 2009; Elfert \& Bormann, 2010; Ghaffari, Keesstra,

55 Ghodousi, \& Ahmadi, 2010), surface and subsurface flow regimes (base flow) (A., B., \& J., 2011;

56 Tu, 2009), surface roughness (A., B., \& J., 2011; Feddema, et al., 2005) and peak runoff (A., B., \&

57 J., 2011; Burch, Bath, Moore, \& O'Loughlin, 1987) and flood frequency and magnitude (A., B., \&

58 J., 2011; Ward, Renssen, Aerts, van Balen, \& Vandenberghe, 2008; Remo, Pinter, \& Heine;

59 Benito, Rico, Sanchez-Moya, Sopeña, THorndycraft, \& Barriendos, 2010; Qiu, Jia, Zhao, Wang,

60 Bennett, \& Zhou, 2010).

61 Similarly, based on Kebede Wolka et al., (2015), Enset-Based land use systems (EBLUS) can

62 reduce the rain drop impact equivalent to the forest and it exhibited a good carbon stock

63 equivalent to high-vegetation areas (Mesfin, Osamu, Christine, \& Kumelachew, 2017; Mbow,

64 Van Noordwijk, Luedeling, Neufeldt, Minang, \& Kowero, 2014) that modifies the infiltration and

65 water holding capacity of the soil for a longer period (Barbora \& Jaroslava, 2014) which in turn

66 influences the curve number (CN) of Meki river watershed. 
67 The socio-economic (Shiferaw Feleke, 2003), yield and inputs required (Uloro \& Mengel, 2014),

68 EBLUS as a food security tool and as a sources of income (Mesfin, Osamu, Christine, \&

69 Kumelachew, 2017; Mbow, Van Noordwijk, Luedeling, Neufeldt, Minang, \& Kowero, 2014;

70 Tilahun \& Robert, 2006; Anita, et al., 1996), the physiological (Admasu Tsegaye 1 and

71 P.C.Struik2, 2003), ecosystem services (Mesfin, Osamu, Christine, \& Kumelachew, 2017),

72 agronomy (Admasu, 2007), breeding (James Harrison 1, 2014), pathology (Bridge, 1992),

73 postharvest (Yirmaga, 2013) and soil nutrition (Elias, 2011) aspect of EBLUS are studied.

74 The Relative impact of EBLUS on surface water has not been established and quantified (Anita,

75 et al., 1996; Uloro \& Mengel, 2014) and the impact of EBLUS changes on hydrological processes

76 are not fully understood (A., B., \& J., 2011; Wang, Liu, Kubota, \& Chen, 2007) and contribution

77 of EBLUS to modify the CN responsible to model peak runoff (Merwade V., 2012) is not studied

78 formerly in the Meki river watershed.

79 Considering the importance of Meki river watershed and its role in contributing to the

80 sustainability of lake Ziway, detailed watershed modeling and analysis are needed including an

81 assessment of how the change in EBLUS at different scales (e.g., from the hydrologic response

82 unit to the basin scale) influenced the $\mathrm{CN}$ in the watershed to understand the underlying

83 mechanisms and to establish theory regarding the effects of EBLUS on CN of Meki river

84 watershed.

85 Therefore, the aim of this study is to articulate the influence of Enset-Based land use system

86 (EBLUS) on Curve number (CN) and to develop a model for HSG based CN matrix of EBLUS 
87 relative to other land use systems with established hydrological characteristics in Meki river

88 watershed.

$90 \quad$ 2.1. Study area description

91 Meki river watershed is found in the western part of lake Ziway between $7^{\circ} 45^{\prime} \mathrm{N}$ to $8^{0} 30^{\prime} \mathrm{N}$ and

$9238^{\circ} 10^{\prime} \mathrm{E}$ to $39^{\circ} 00^{\prime} \mathrm{E}$ as shown in Figure 1in the Central Rift Valley (CRV) of Ethiopia and the

93 watershed has a mean elevation of 2169 m.a.s.l, the mean annual rainfall ranges from $824 \mathrm{~mm}$

94 to $1292 \mathrm{~mm}$ and the mean monthly temperature varies between $15^{\circ} \mathrm{C}$ and $29^{\circ} \mathrm{C}$, the mean

95 relative humidity of $60 \%$, average wind speed of $1.66 \mathrm{~m} / \mathrm{s}$ and average sunshine hour of $7.3 \mathrm{hrs}$

96 (Alemu Beyene et al, 2020; ENMA, 2017; Oliver et al., 2007). 


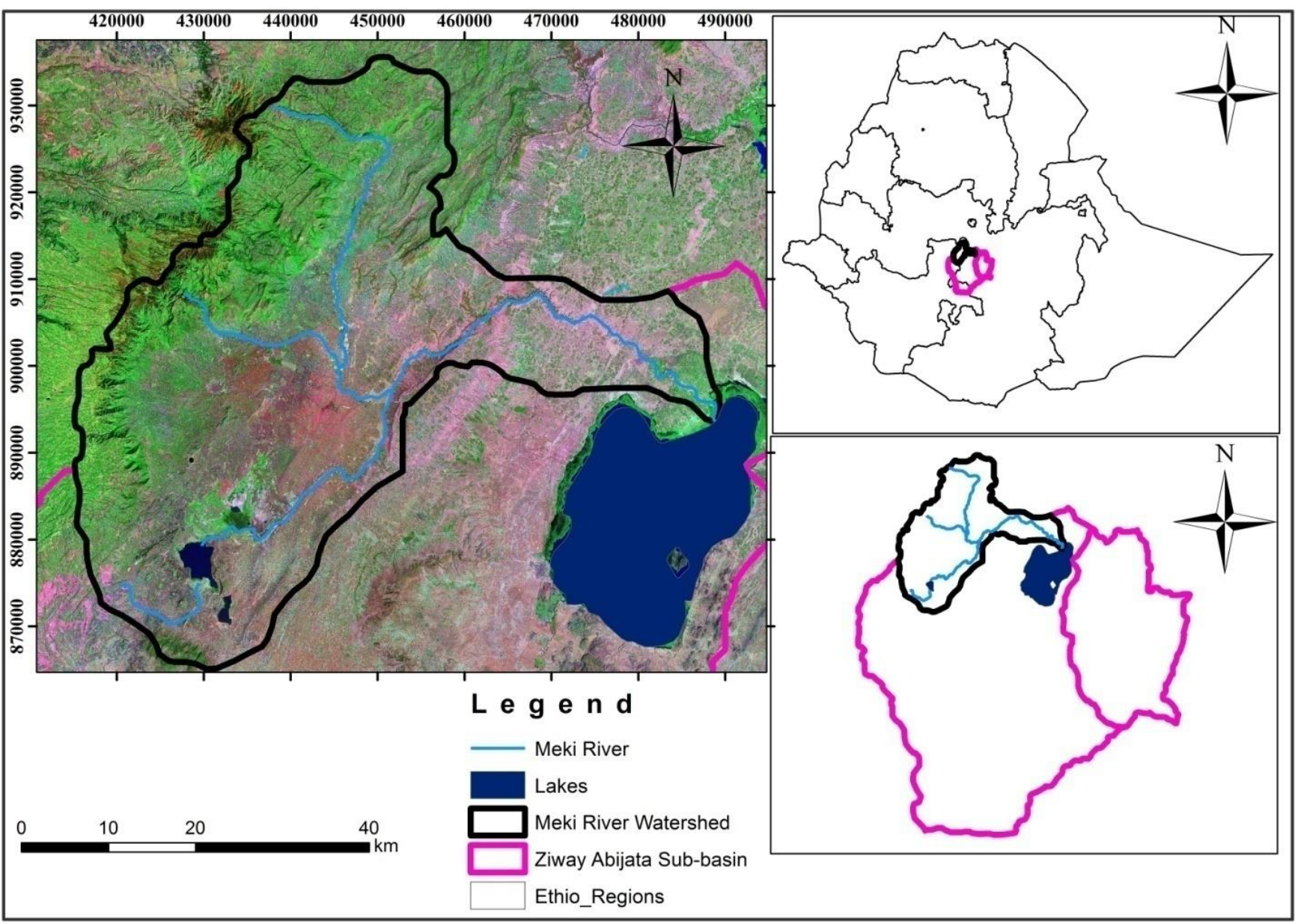

$98 \quad$ Figure 1: Study area map

\subsection{Research Framework}

100 Soil organic carbon and Land use are the critical factors to influence the infiltration capacity of

101 the soil (Yimer, 2008; A.O.Ibeje, 2018). The mean steady state infiltration rates of farmlands,

102 bamboo fields and forestland are $1.98 \mathrm{~cm} / \mathrm{h}, 2.44 \mathrm{~cm} / \mathrm{h}$ and $2.43 \mathrm{~cm} / \mathrm{h}$ respectively (A.O.Ibeje,

103 2018). This shows that the infiltration rate of the soil is under the influence of land use and also

104 the land use change can affect the infiltration capacity of the soil (A.O.Ibeje, 2018).

105 Enset-Based land use system (EBLUS) considered in the land cover classification process using

106 ERDAS imagine software with maximum likelihood algorithm and used to model the CN matrix 
107 of Meki river watershed. Therefore, this study articulates the influence of EBLUS on CN of Meki

108 river watershed and model the CN matrix for EBLUS as shown in the Flow diagram presented in

109 Figure 2.

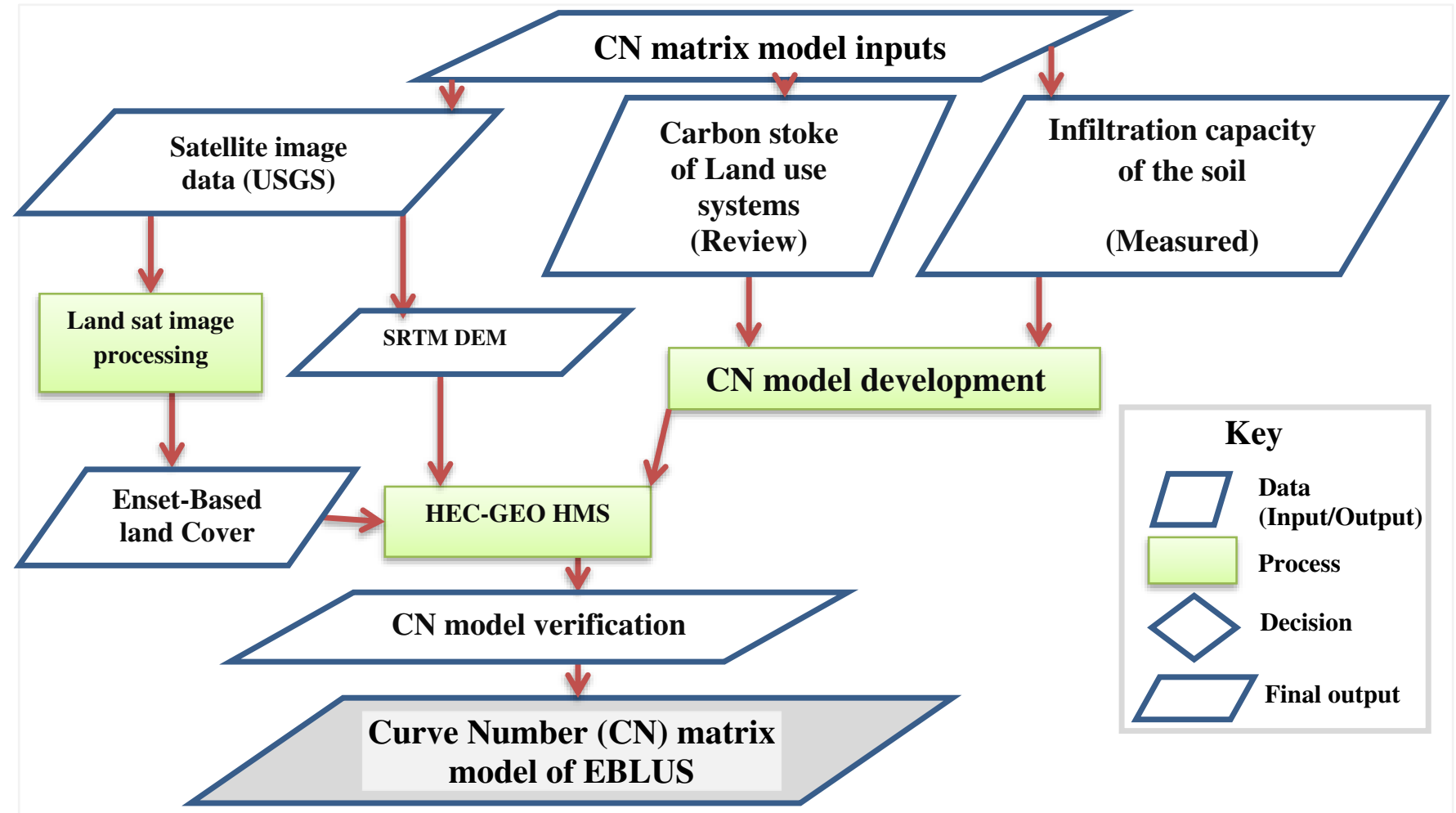

111 Figure 2: CN matrix model flow diagram

\subsection{Field measurement and analysis of infiltration capacity of LUS}

\section{Sample site selection criteria}

114 Measuring and mapping of vegetation zone based infiltration rate of the soil under different

115 land use systems to evaluate their relative hydrological influence are achieved using Amozi-

116 meter in the labor intensive field work. The soil type (soil texture) is one of the bases for sample

117 site selection next to vegetation zone. 

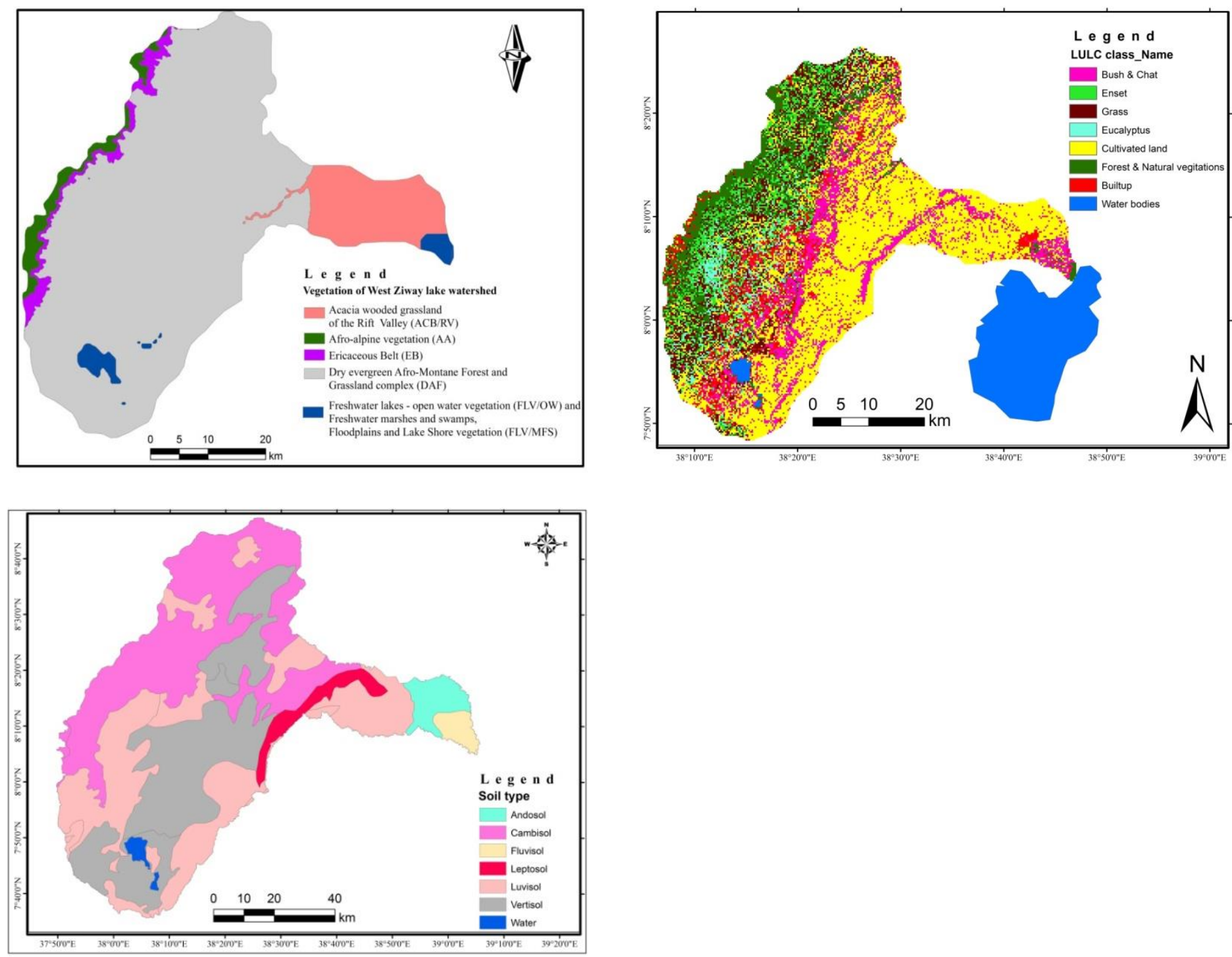

118 Figure 3: Dominant Vegetation zone, Land cover \& soil type maps of the study area

119 Preliminary GPS based site assessment was carried out starting from the highest point of the

120 watershed to Lake Ziway which is characterized by high elevation differences from 1633 m.a.s.I

121 at the gauging station of Meki river discharge to 3612m.a.s.I at Zebidar Mountain which can

122 give enough head and opportunity for water resources development options. 
123 In the process of field measurement site selection; Vegetation zone, dominant LUS and

124 Dominant soil types in the study area as shown in Figure 3 are considered as the main factors

125 influencing the infiltration capacity of the soil and the sampling matrix is prepared after the

126 overlay of those maps together so as to choose appropriate locations to organize the proposed

127 field measurement.

128 Sampling and Measurement techniques

129 In order to get and compare the hydrological characteristics of EBLUS, the following sampling

130 matrix was prepared as shown in Table 1. In the process of sampling, land use class is crucial for

131 the relative comparison of hydrological components (infiltration capacity) with replication.

132 The study area is classified in to eight land cover classes that include forest and natural

133 vegetation LUS, grass LUS, EBLUS, eucalyptus with sparse vegetation LUS, cultivated LUS, built-

134 up and degraded LUS but due to non-availability of data for all eight LUSs and for the ease of

135 sampling, the LUSs are aggregated as Cultivated LUS, Built-up \& Degraded LUS, Grass \&

136 Plantation LUS, EBLUS and Natural Forest LUS for the sampling purposes. The soil type data is

137 collected from MOWIE GIS section and Vertisol, Cambisol, Luvisol and Leptosol are considered

138 as the dominant four soil types in the watershed. The soil type is verified by harmonized world

139 soil database (HWSD).

140 The vegetation zones are combined with dominant soil types as vegetation zone 1 with soil type

1411 (Z11) up to vegetation zone 3 with soil type 4 (Z34). Vegetation zones are expressed as Afro-

142 alpine as vegetation zone 1, Dry Afro-montane as vegetation zone 2 and Acacia wooded grass 
143 land of rift valley as vegetation zone 3 verified in the field as shown in Figure 4 below and the

144 dominant soil types considered are Vertisol, Cambisol, Luvisol and Leptosol and called to be soil

145 type 1 , soil type 2 , soil type 3 and soil type 4 respectively as shown in Table 1.
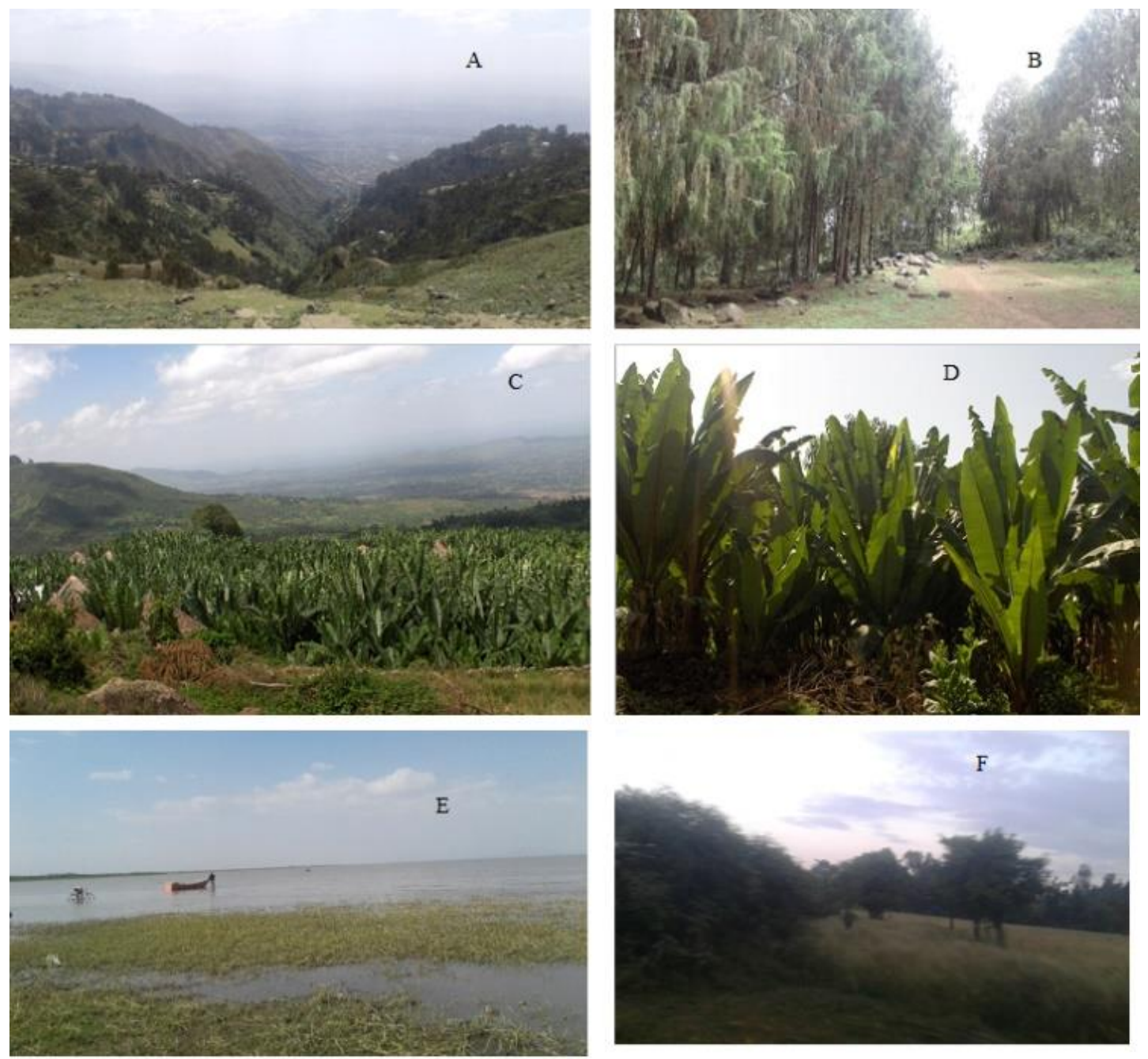

147 Figure 4: Vegetation zone verification assessment

$148 \quad \mathrm{~A}=$ Divide line at western end of the watershed where more than half part of the watershed is 149 visible (Silti zone)

$150 \quad$ B \& F = Western upper part of Meskan woreda (Yewutin \& Yetebon respectively)

$151 \quad \mathrm{C}=$ Found around Eastern Meskan woreda and Western Sodo woreda 
$152 \quad \mathrm{D}=$ Scene at Chohamba Meskan woreda

$153 \quad E=$ Conversion from lake to wetland (Lake Ziway)

Table 1: Sampling points based on vegetation zone, Dominant soil type and Dominant LUS

\begin{tabular}{|c|c|c|c|c|c|c|}
\hline & & \multicolumn{5}{|l|}{ Land Cover } \\
\hline & & $\begin{array}{l}\text { Cultivated } \\
\text { LUS }\end{array}$ & $\begin{array}{l}\text { Builtup\& } \\
\text { Degraded LUS }\end{array}$ & $\begin{array}{l}\text { Grass \& Planted Forest } \\
\text { LUS }\end{array}$ & EBLUS & $\begin{array}{l}\text { Natural Forest } \\
\text { LUS }\end{array}$ \\
\hline \multirow{12}{*}{ 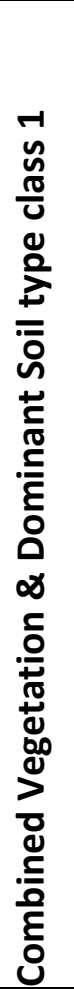 } & Z11 & CZ11 & BZ11 & GZ11 & EZ11 & NZ11 \\
\hline & Z12 & CZ12 & BZ12 & GZ12 & EZ12 & NZ12 \\
\hline & Z13 & CZ13 & BZ13 & GZ13 & EZ13 & NZ13 \\
\hline & Z14 & CZ14 & BZ14 & GZ14 & EZ14 & NZ14 \\
\hline & $\mathrm{Z} 21$ & CZ21 & BZ21 & GZ21 & EZ21 & NZ21 \\
\hline & $\mathrm{Z22}$ & CZ22 & BZ22 & GZ22 & EZ22 & NZ22 \\
\hline & $\mathrm{Z} 23$ & CZ23 & BZ23 & GZ23 & EZ23 & NZ23 \\
\hline & Z24 & CZ24 & BZ24 & GZ24 & EZ24 & NZ24 \\
\hline & Z31 & CZ31 & BZ31 & GZ31 & EZ31 & NZ31 \\
\hline & Z32 & CZ32 & BZ32 & GZ32 & EZ32 & NZ32 \\
\hline & Z33 & CZ33 & BZ33 & GZ33 & EZ33 & NZ33 \\
\hline & Z34 & CZ34 & BZ34 & GZ34 & EZ34 & NZ34 \\
\hline
\end{tabular}

There are about 60 sampling possibilities, but EBLUS is not common the acacia wooded part of the watershed for which zones Z31 to Z34 to all LUSs are not applicable in this research.

The resulting sampling points are Z11 up to Z24 (8 combined zones of two vegetation zones and four dominant soil types) for five LUSs which results in 40 sampling points replicated to four fold to make it representative and to reduce human and instrumental errors.

\footnotetext{
${ }^{1}$ CZ23 refers to Cultivated LUS in vegetation zone two (Dry afro-montane) and soil type three (Luvisol)
} 
The infiltration data collected from those sampling points using Amozi-meter as shown in Figure 5. Hence, 160 samples were collected in the field excluding the lower zone of the watershed since it has no sufficient EBLUS to be considered and the result is analyzed and mapped using ArcGIS 10.1 for their hydrological characteristics of different land use systems compared with EBLUS.

Enset-Based land use system (EBLUS) was not included in all former land use studies and now in this portion more focus is deputed to the infiltration capacity of EBLUS relative to all land use systems in Meki river watershed. Amozi-meter is used to measure the infiltration capacity of soil under each land use system, including EBLUS as shown in Figure 5 and considered to model CN matrix of EBLUS.

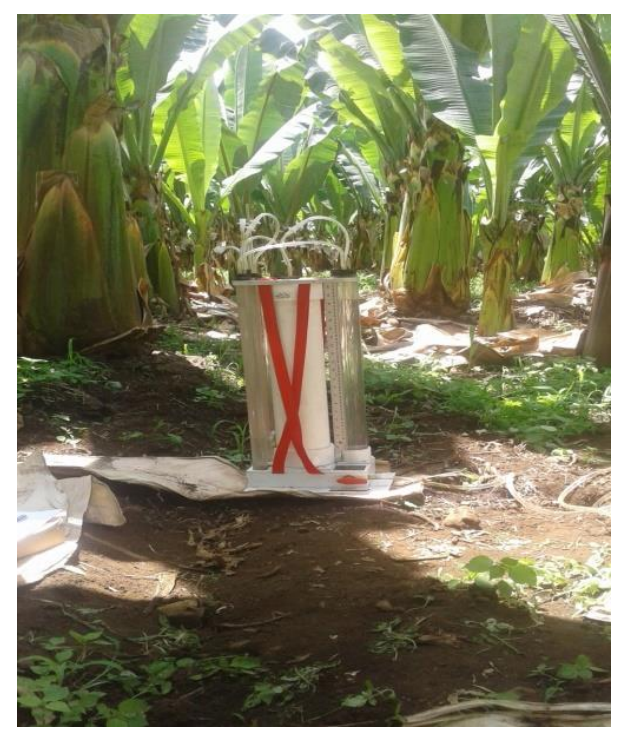

Figure 5: Amozi-meter infiltration measurement of EBLUS

The hole dug to the level to which the water is released into the ground through sensor at the tip of the plastic pipe attached to the main tanker of the Amozi-meter. The level of digging the 
hole depends on the number of pipes filled to keep the balance pressure which is equivalent to $0.5 \mathrm{~m}$ deep for one pipe. The main tanker was filled from the top with clean water to protect blockage of flowing pipes of the instrument to the sensor.

The water is released to flow down to the ground and time and depth of flow recorded using a stopwatch and gauge fitted to the instrument respectively based on the procedural manual.

\subsection{Review of Carbon stoke of Land use systems}

Published articles are reviewed to get the carbon stock of different land use systems which accounts EBLUS. According to Mesfin et al, 2017, carbon stoke of land uses are measured and reported as shown in Table 2 and considered to develop the CN of EBLUS.

Table 2: Carbon stock of different land use systems (Source: Mesfin et al, 2017)

\begin{tabular}{|l|l|}
\hline Land Cover/Land Use & Carbon stock (ton/yr) \\
\hline Open Water & 0 \\
\hline Built-up, Medium Intensity LUS & 132 \\
\hline Natural Forest LUS & 45,714 \\
\hline Grasslands (Pasture) \& plantations LUS & 8350 \\
\hline Cultivated LUS & 19,950 \\
\hline Enset-Based LUS & 77,286 \\
\hline
\end{tabular}




\subsection{Review of HSG based curve number of land use systems}

$\mathrm{CN}$ matrix is developed for all land use systems except EBLUS as shown in Table 3 that is used to develop a relation among the model the $\mathrm{CN}$ matrix for EBLUS relative to other land use systems with predetermined $\mathrm{CN}$.

Table 3: Curve number lookup table (ERA, 2013; Chow, 1988)

\begin{tabular}{|l|l|l|l|l|}
\hline & \multicolumn{4}{|l|}{ Hydrologic Soil Group } \\
\hline Land Cover/Land Use & A & B & C & D \\
\hline Open Water & 100 & 100 & 100 & 100 \\
\hline Developed, Open Space & 39 & 61 & 74 & 80 \\
\hline Developed, Low Intensity & 57 & 72 & 81 & 86 \\
\hline Developed, Medium Intensity & 77 & 85 & 90 & 92 \\
\hline Developed, High Intensity & 98 & 98 & 98 & 98 \\
\hline Barren Land, Rock, Sand, Clay & 63 & 77 & 85 & 88 \\
\hline Deciduous Forest & 36 & 60 & 73 & 79 \\
\hline Evergreen Forest & 36 & 60 & 73 & 79 \\
\hline Mixed Forest & 36 & 60 & 73 & 79 \\
\hline Scrub/Shrub & 35 & 56 & 70 & 77 \\
\hline Grasslands, Herbaceous & 39 & 61 & 74 & 80 \\
\hline Pasture, Hay & 49 & 69 & 79 & 84 \\
\hline Cultivated Crops & 67 & 78 & 85 & 89 \\
\hline Woody Wetlands & 100 & 100 & 100 & 100 \\
\hline Emergent Herbaceous Wetlands & 100 & 100 & 100 & 100 \\
\hline
\end{tabular}

The $\mathrm{CN}$ matrix of the dominant land use systems are used in modeling the $\mathrm{CN}$ matrix of EBLUS in Meki river watershed. 


\subsection{CN Matrix Model development method}

The formerly developed CN matrix for all land use systems (LUSs) except EBLUS, infiltration capacity of the soil under all LUSs including EBLUS and carbon stock of the soil under all LUSs including EBLUS are used to develop a model for CN matrix of EBLUS relative to other LUSs with predetermined $\mathrm{CN}$ using Microsoft excel.

\subsection{Preprocessing and $\mathrm{CN}$ model verification procedure in HEC-GeoHMS}

Soil conservation service curve number grid is used by many hydrologic models to extract the curve number for watersheds (Fleming \& Brauer, 2018; Merwade, 2012) for further analysis of watershed parameters and runoff modeling. To produce the $\mathrm{CN}$ grid several activities are expected that include watershed delineation, land use grid preparation, HSG grid preparation, merge the land use and soil data, create $\mathrm{CN}$ lookup table and finally creating the $\mathrm{CN}$ grid for Meki river watershed.

\subsubsection{Delineation of the watershed from DEM}

Meki river watershed and sub-watersheds are automatically extracted from Digital Elevation Model (DEM) and the DEM is preprocessed to produce the watershed fill, flow direction, flow accumulation, stream definition, stream segmentation, combined stream link, sink link, catchment grid delineation, catchment polygon processing, flow length, slope, Elevation, aspect, contour line, drainage line processing and adjoinment catchment processing, etc are derived using HEC-GeoHMS model of Arc GIS 10.1(Iliasse Khaddor \& Adil HafidiAlaoui, 2014). 
The project setup is generated using the outlet point at Lake Ziway by providing the data at the preprocessing phase of the project. Basin merge and river merge processes are taken place to increase consistency and convenience of the result output.

According to Fleming and Brauer (2018), in order to perform CN modeling, various types of information are required that includes watershed parameters from DEM, HSG and LUSs and the CN grid is used by many hydrologic models (Merwade, 2012).

\subsubsection{Land use data preparation for $\mathrm{CN}$ grid}

Land use map was generated using Land sat image data $(30 \mathrm{~m})$ supported by Google earth. GPS based field visit is performed to collect data to train ERDAS 2014 to classify the images with maximum likelihood clustering algorithm of supervised classification method (Iliasse and Adil , 2014; Fleming and Brauer 2018) and eight Land use systems are identified as shown in

Figure 6 and reclassified into five classes as shown in According to Fleming and Brauer (2018) and Merwade (2012), the Spatial Analyst Tools in Arc Toolbox is used to implement reclassification 
Table 4 based on the USGS land cover institute $\left(\mathrm{LCl}^{2}\right)$ and modified to include the recently recognized EBLUS (Fleming and Brauer, 2018; Okirya Martin, Albert Rugumayo and Janka Ovcharovichova, 2012; Merwade, 2012).

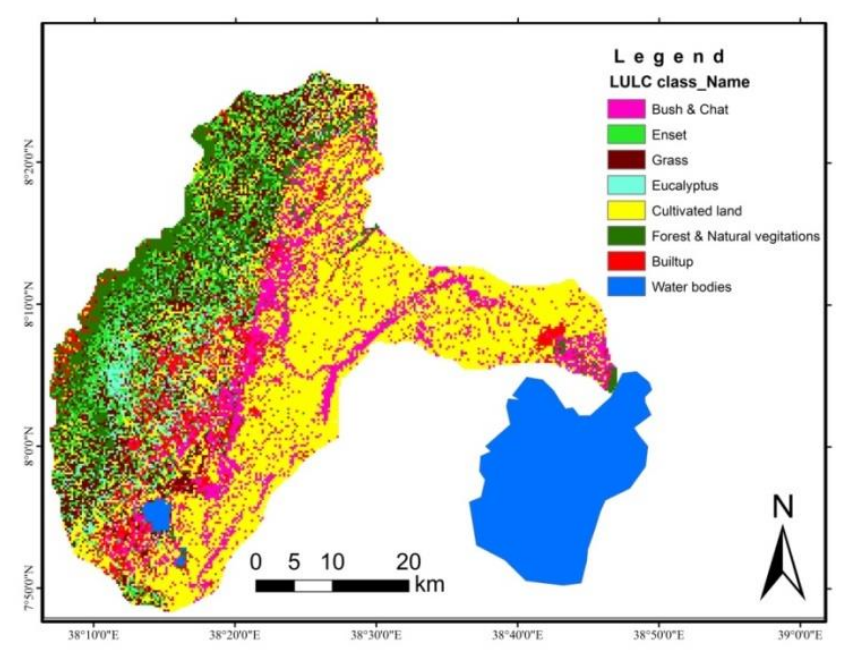

Figure 6: Land use system of the area for $\mathrm{CN}$ mapping

According to Fleming and Brauer (2018) and Merwade (2012), the Spatial Analyst Tools in Arc Toolbox is used to implement re-classification

${ }^{2}$ http://landcover.usgs.gov/classes.php 
Table 4: Land use reclassification based on USGS land cover institute (LCI) with modification

\begin{tabular}{|l|l|l|l|}
\hline & Land cover classification & Revised classification \\
\hline Number & Description & 1 & Description \\
\hline $\mathbf{1 1}$ & Water bodies & & Water \\
\hline $\mathbf{9 5}$ & Wetlands with herbaceous plants & \\
\hline $\mathbf{2 1}$ & Developed, Open space LUS & 2 & Built ups \\
\hline $\mathbf{2 2}$ & Developed, Low and medium intensity LUS & & \\
\hline $\mathbf{2 3}$ & Developed, High intensity LUS & & \\
\hline $\mathbf{4 3}$ & Mixed forest LUS & 3 & Forest\& \\
\cline { 1 - 1 } & Natural forest LUS & & vegetation \\
\hline $\mathbf{4 1}$ & Plantation LUS & & Agricultural \\
\hline $\mathbf{3 1}$ & Bare land LUS & & \\
\hline
\end{tabular}




\begin{tabular}{|l|l|l|l|}
\hline $\mathbf{8 2}$ & Cultivated land LUS & & \\
\hline $\mathbf{5 2}$ & Grass land LUS & & \\
\hline & Enset & 6 & EBLUS \\
\hline
\end{tabular}

In the reclassification window, confirm the Input raster is LULC_2017_March2019Recl field is Class_Name, and then manually assign the new numbers from Table 4 as shown in Figure 7 and the output raster is saved as LULC_2017_March2019Recl.

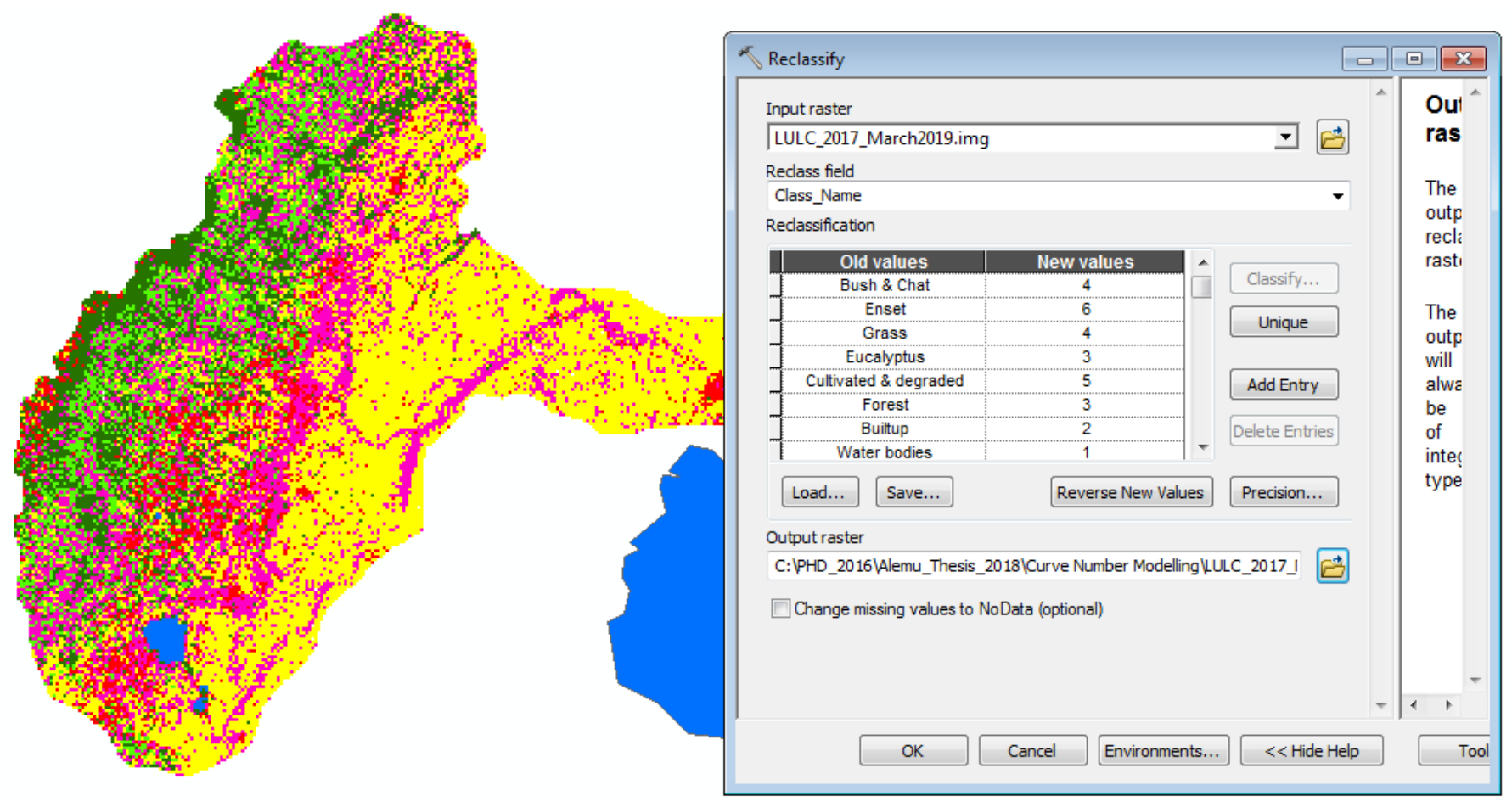

Figure 7: Reclassification window with assigned new values

The final steps in processing land use data were converting the reclassified land use grid (raster) into a polygon feature class following the procedure in Conversion Tools of the Arc Toolbox and assign the new value. 


\subsubsection{Hydrologic soil groups data preparation for $\mathrm{CN}$ grid}

The hydrological soil data are collected from Ethiopia Ministry of Water, Irrigation and Energy (MOWE, 2013) as shown in Figure 8 and verified by HWSD viewer. The soil categories such as Cambisol, Andosol, Fluvisol, Leptosol, Vertisol and Luvisol are identified and hydrologic soil group is assigned to each category based on US Natural Resource Conservation Service (NRCS) that may fall into four hydrologic soil groups (HSG) (A, B, C and D): high, moderate, slow and very slow infiltration rates respectively (USDA-NRCS, 1986).

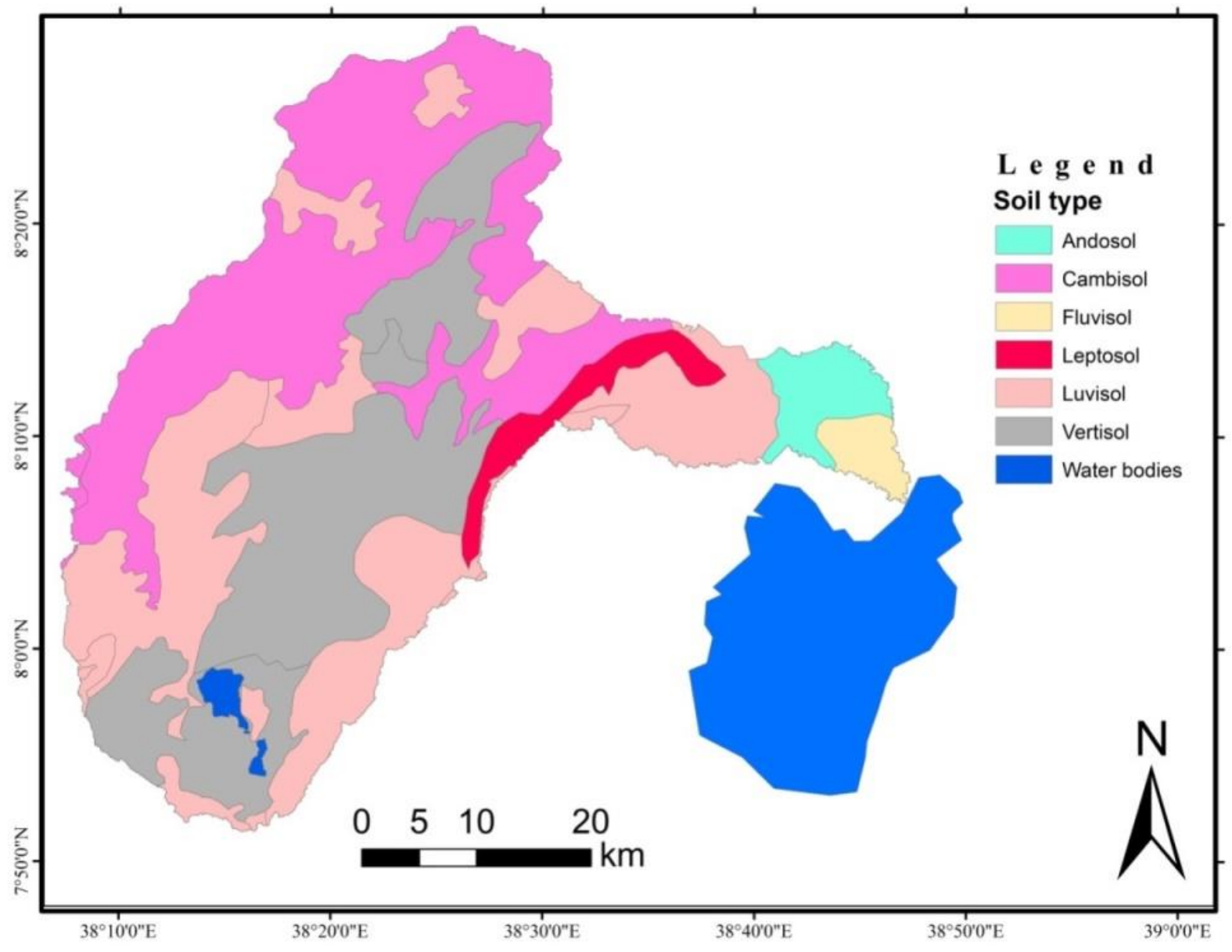

Figure 8: Soil map of the area (MWIE, 2017) 
Add Soil_WZ_2018_1 feature class from spatial dataset collected from Ethiopia MOWIE and in its attribute table create an empty field for storing soil group data as shown in Table 5. Hence the hydrologic soil group data can be populated to Soil_WZ_2018_1 after identifying the type of soil with its corresponding description.

Ethiopian Road Authority (2013) manual is used to generate the relationship of soil type and hydrologic soil group of Meki river watershed and also verified by HWSD viewer and also shape file data acquired from MOWIE as shown in Table 5.

Table 5: Hydrologic soil group of different soil types (ERA, 2013)

\begin{tabular}{|l|l|l|l|l|l|}
\hline Soil Types & Hydrologic Soil & Soil Types & HSG & Soil Types & HSG \\
\hline Orthic Acrisols & B & & & & \\
\hline Chromic Cambisols & B & Calcaric Fluvisols & B & Eutric Nitosols & B \\
\hline Dystric Cambisols & B & Eutric Fluvisols & B & Dystric Histosols & D \\
\hline Eutric Cambisols & B & Chromic Luvisols & B & Eutric Histosols & D \\
\hline Humic Cambisols & C & Orthic Luvisols & B & Cambric Arenosols & A \\
\hline Calcic Cambisols & B & Vertic Luvisols & C & Calcaric Regosols & A \\
\hline Vertic Cambisols & B & Dystric Nitosols & B & Eutric Regosols & A \\
\hline Calcic Chernozems & B & Caloic Xerosols & B & Humic Andosols & B \\
\hline Rendzinas & D & Luvic Xerosols & C & Mollic Andosols & B \\
\hline Haplic Phaeozems & C & Gypsic Yermosols & B & Vitric Andosols & B \\
\hline
\end{tabular}




\begin{tabular}{|l|l|l|l|l|l|}
\hline Luvic Phaeozems & C & Orthic Solonchaks & B & Haplic Xerosols & B \\
\hline Lithosols & D & Pellic Vertisols & D & & \\
\hline
\end{tabular}

Accordingly, the HSG is assigned to each of the six soil types identified in the watershed as shown in Figure 9. During the assignment the HSG of Leptosol is assigned after referring the field characteristics of the soil and it has more similarity to Luvisol with its insignificant areal coverage to influence the value of the curve number and hence HSG of $\mathrm{C}$ is assigned to it.

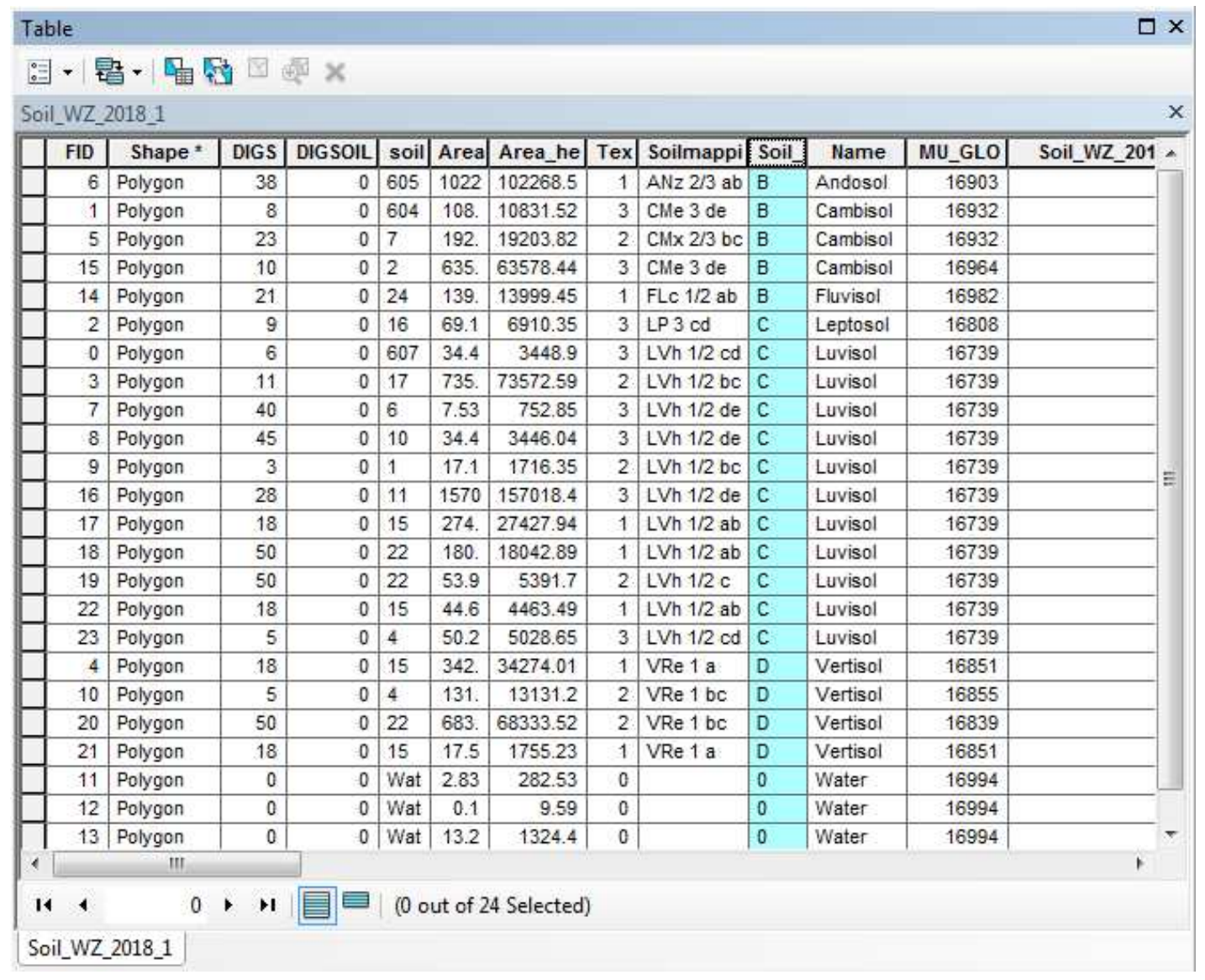

Figure 9: Hydrologic soil group (HSG) assignment 
Editing the Soil_WZ_2018_1 and transferring HSG, now we have a Soil Code (soil group) assigned to each polygon in Soil_WZ_2018_1. Following soil group assignment, create four more fields named PctA, PctB, PctC, and PctD all of type short integer in Soil_WZ_2018_1 feature class. For each feature (polygon) in Soil_WZ_2018_1 PctA will define what percentage of area within the polygon has soil group A, PctB will define what percentage of area within the polygon will have soil group B and so on (USDA-NRCS, 1986). This is critical when we have polygons with more than one soil group (for eg. A-B-A/D would mean that group A, group B and group A/D soils are found in one polygon; A/D would mean the soil behaves as $A$ when drained and as D when not drained, and so on). If we have classifications such as these, we need to define how much area of a polygon is A/B/C/D.

For Meki river watershed area we have only one soil group assigned to each polygon so a polygon with soil group " $A$ " will have $P c t A=100, \operatorname{PctB}=0, \operatorname{Pct} C=0$, and $\operatorname{PctD}=0$. Similarly for a polygon with soil group $D$, only PctD $=100$, and other three Pcts are 0 . Now populate PctA, PctB, PctC and PctD based on Soil Code for each polygon. You can select features based on Soil Code and then use field calculator to assign numbers to polygons. The resulting attribute table should look like as shown in Figure 10. 


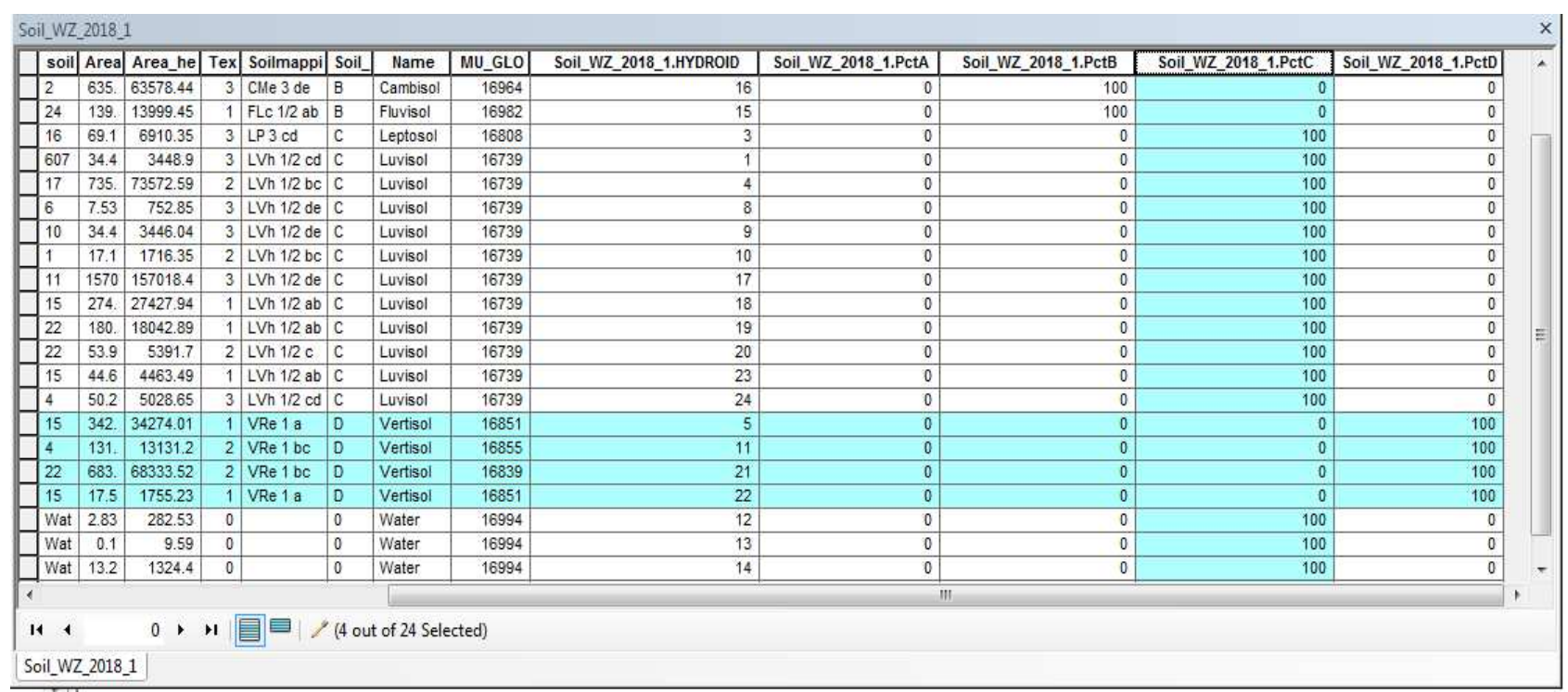

Figure 10: Standard curve number matrix assignment for different soil groups

The preparation of soil data is over at this point. The next step is to merge/union both soil data and land use data to create polygons that have both soil and land use information. Save the map document.

\subsubsection{Merging of Soil and Landuse Data}

To merge/union soil and land use data, use the Union tool in Arc Tool box available under Analysis Tools - Overlay. Browse/drag Soil_WZ_2018_1 and LULC_2017_March2019Pol as input features, name the output feature class as "Meki_Soil_LU”, leave the default options, and click OK as shown in Figure 11. 


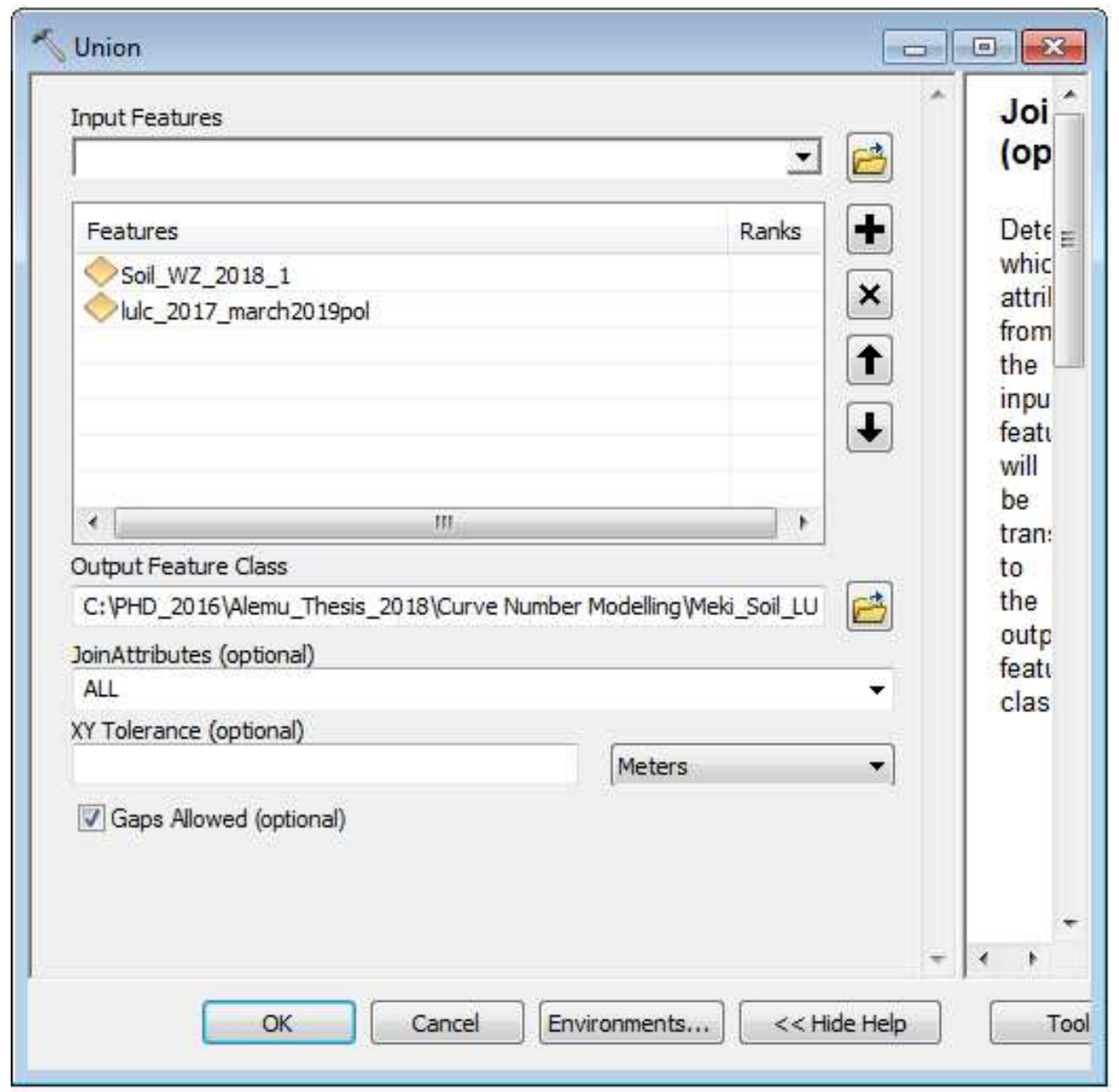

Figure 11: Soil land use union (Merge) of the watershed

The result of union/merge features inherit attributes from both feature classes that are used as input. However, if the outer boundaries of input feature classes do not match exactly, the resulting merged feature class (Meki_Soil_LU in this case) usually will have features that will have attributes from only one feature class called "slivers" because the other feature do not exist in this area.

If we open the attribute table for Meki_Soil_LU, we will find that there are several sliver polygons in this feature class that have attributes only from LULC_2017_March2019Pol and the soil attributes are empty, and vice versa as shown in Figure 12: 


\begin{tabular}{|c|c|c|c|c|c|c|c|c|c|c|c|c|c|c|c|c|c|c|c|c|c|c|}
\hline Table & & & & & & & & & & & & & & & & & & & & & & $\square \times$ \\
\hline$:=$. & | 啿- & 㽞制 & 4 & $x$ & & & & & & & & & & & & & & & & & & \\
\hline Meki_ & Soil_LU & & & & & & & & & & & & & & & & & & & & & $x$ \\
\hline $\mathrm{Fl}$ & Shape ${ }^{*}$ & FID_lulc_ & ID & GRID & Valu & FID_Soil_w & DIG & DIGS & soil & Are & Are & Text & Soilm & Name & MU_G & HSG & HYDROID & \begin{tabular}{|l|} 
PctA \\
\end{tabular} & PctB & PctC & PctD & A \\
\hline 0 & Polygon & 0 & 1 & 5 & 5 & -1 & 0 & 0 & & 0 & 0 & 0 & & & 0 & & 0 & 0 & 0 & 0 & 0 & 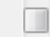 \\
\hline 1 & Polygon & 1 & 2 & 4 & 4 & -1 & 0 & 0 & & 0 & 0 & 0 & & & 0 & & 0 & 0 & 0 & 0 & 0 & \\
\hline 2 & Polygon & 2 & 3 & 6 & 6 & -1 & 0 & 0 & & 0 & 0 & 0 & & & 0 & & 0 & 0 & 0 & 0 & 0 & \\
\hline 3 & Polygon & 4 & 5 & 3 & 3 & -1 & 0 & 0 & & 0 & 0 & 0 & & & 0 & & 0 & 0 & 0 & 0 & 0 & \\
\hline 4 & Polygon & 6 & 7 & 5 & 5 & -1 & 0 & 0 & & 0 & 0 & 0 & & & 0 & & 0 & 0 & 0 & 0 & 0 & \\
\hline 5 & Polygon & 7 & 8 & 4 & 4 & -1 & 0 & 0 & & 0 & 0 & 0 & & & 0 & & 0 & 0 & 0 & 0 & 0 & \\
\hline 6 & Polygon & 10 & 11 & 5 & 5 & -1 & 0 & 0 & & 0 & 0 & 0 & & & 0 & & 0 & 0 & 0 & 0 & 0 & \\
\hline 7 & Polygon & 11 & 12 & 4 & 4 & -1 & 0 & 0 & & 0 & 0 & 0 & & & 0 & & 0 & 0 & 0 & 0 & 0 & \\
\hline 8 & Polygon & 14 & 15 & 3 & 3 & -1 & 0 & 0 & & 0 & 0 & 0 & & & 0 & & 0 & 0 & 0 & 0 & 0 & \\
\hline 9 & Polygon & 15 & 16 & 4 & 4 & -1 & 0 & 0 & & 0 & 0 & 0 & & & 0 & & 0 & 0 & 0 & 0 & 0 & \\
\hline 1 & Polygon & 16 & 17 & 5 & 5 & -1 & 0 & 0 & & 0 & 0 & 0 & & & 0 & & 0 & 0 & 0 & 0 & 0 & \\
\hline 1 & Polygon & 19 & 20 & 3 & 3 & -1 & 0 & 0 & & 0 & 0 & 0 & & & 0 & & 0 & 0 & 0 & 0 & 0 & \\
\hline 1 & Polygon & 22 & 23 & 6 & 6 & -1 & 0 & 0 & & 0 & 0 & 0 & & & 0 & & 0 & 0 & 0 & 0 & 0 & \\
\hline 1 & Polygon & 23 & 24 & 4 & 4 & -1 & 0 & 0 & & 0 & 0 & 0 & & & 0 & & 0 & 0 & 0 & 0 & 0 & \\
\hline 1 & Polygon & 24 & 25 & 5 & 5 & -1 & 0 & 0 & & 0 & 0 & 0 & & & 0 & & 0 & 0 & 0 & 0 & 0 & \\
\hline 1 & Polygon & 25 & 26 & 4 & 4 & -1 & 0 & 0 & & 0 & 0 & 0 & & & 0 & & 0 & 0 & 0 & 0 & 0 & \\
\hline 1 & Polygon & 32 & 33 & 6 & 6 & -1 & 0 & 0 & & 0 & 0 & 0 & & & 0 & & 0 & 0 & 0 & 0 & 0 & \\
\hline 1 & Polygon & 33 & 34 & 5 & 5 & -1 & 0 & 0 & & 0 & 0 & 0 & & & 0 & & 0 & 0 & 0 & 0 & 0 & \\
\hline 1 & Polygon & 46 & 47 & 6 & 6 & -1 & 0 & 0 & & 0 & 0 & 0 & & & 0 & & 0 & 0 & 0 & 0 & 0 & \\
\hline 1 & Polygon & \begin{tabular}{l|}
47 \\
\end{tabular} & 48 & 4 & 4 & -1 & 0 & 0 & & 0 & 0 & 0 & & & 0 & & 0 & 0 & 0 & 0 & 0 & \\
\hline 2 & Polygon & 48 & 49 & 3 & 3 & -1 & 0 & 0 & & 0 & 0 & 0 & & & 0 & & 0 & 0 & 0 & 0 & 0 & \\
\hline 2 & Polygon & 49 & 50 & 5 & 5 & -1 & 0 & 0 & & 0 & 0 & 0 & & & 0 & & 0 & 0 & 0 & 0 & 0 & - \\
\hline 14 & 1 & 0. & 1 & 目 & 10 or & ut of 9219 & electe & & & & & & & & & & & & & & & \\
\hline Meki & i_Soil_LU & & & & & & & & & & & & & & & & & & & & & \\
\hline
\end{tabular}

Figure 12: Avoiding sliver (-1) of the soil land use union of the watershed

One way to deal with sliver polygons is to assign missing values to all features or (easiest!) is to just delete them (Merwade, 2012).

\subsubsection{Creating CN Look-up table}

The next step is to prepare a look-up table that will have curve numbers for different combinations of land uses and soil groups. In this case, we will use SCS curve numbers that are available from the literature. The spatial features in conjunction with the lookup table can then be used to create curve number grid (Merwade, 2012).

Create a table named "CNLookUp". In Arc tool box, select Data Management Tools ... Table ... Create Table. Now start the Editor to edit the newly created CNLookUp table, and populate it as shown in Figure 13. 


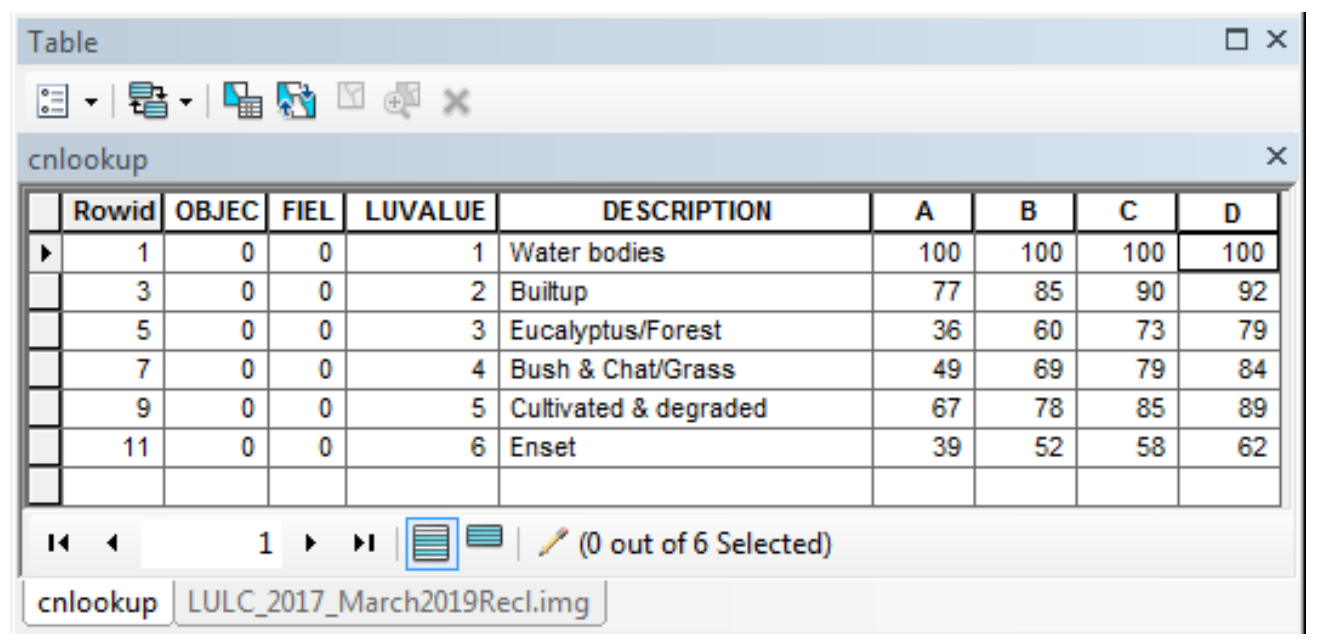

Figure 13: Lookup table considering EBLUS

Columns $A / B / C / D$ store curve numbers for corresponding soil groups for each land use system (LUValue) that are obtained from Ethiopian Road Authority (2013), USDA-NRCS (1986) and the model output for EBLUS.

\subsubsection{Creating CN Grid}

HEC-GeoHMS uses the merged feature class (Meki_Soil_LU) and the lookup table (CNLookUp) to create the curve number grid. A field created in the merged feature class (Meki_Soil_LU) named "LandUse" that will have land use category information to link it to CNLookUp table. We already have this information stored in GRIDCODE field, but HEC-GeoHMS looks for this information in LandUse field. So create a field named LandUse (type: short integer), and populate it by equating it to GRIDCODE.

On the HEC-GeoHMS Project View toolbar, click on Utility ... Create Parameter Grids... Choose the lookup parameter as Curve Number (which is the default), Click OK, and then select the inputs as shown in Figure 14. 


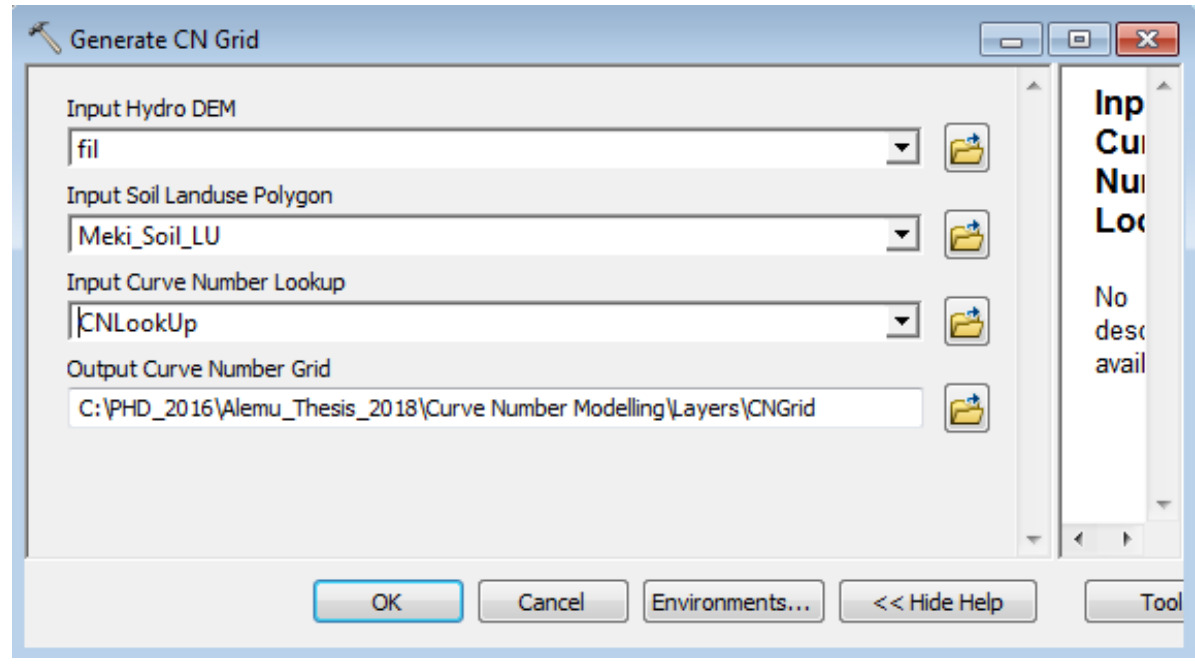

Figure 14: CN generation considering Enset-Based land use system

Fil for Hydro DEM, Meki_Soil_LU (merged soil and land use) for input soil landuse polygon, CNLookUp table for input Curve Number Lookup, and leave the default CNGrid name for the Curve Number Grid.

\subsection{Determination of watershed based curve number}

Curve number is extracted from the soil type and land use data considering EBLUS using HEC-

GeoHMS, which both affect the infiltration capacity of the soil and the Soil data acquired from the Ethiopian Ministry of Water Irrigation and Energy (MWIE) and Landsat image from USGS (Fleming and Brauer, 2018).

The factors of the $\mathrm{CN}$ model developed from the raster format of soil and LUS data with the same coordinate system (UTM WGS $198437^{\circ}$ North) with a spatial resolution of 30m. Finally, the result is extracted and reported for the classified LUS of Meki river watershed and also it is extracted to 34 sub-watersheds and two major growing zones (Enset growing and non-Enset growing zones) of Meki river watershed. 


\section{Result and Discussion}

\subsection{Infiltration capacity of the soil}

Field data were collected, summarized and presented in Error! Reference source not found. of appendix for the infiltration capacity of the soil for different land use systems. The silt loam and clay loam textural classes are dominant in the upper zone while almost all textural classes are found in the middle zone of the watershed. According to Oliver et al 2006, the soil textural class of Meki river watershed is dominantly occupied by Sandy Loam, Silt Loam, Clay Loam and Clay irrespective of the land use systems with a range of infiltration rate values of 20 to $30 \mathrm{~mm} / \mathrm{hr}$, 10 to $20 \mathrm{~mm} / \mathrm{hr}, 5$ to $10 \mathrm{~mm} / \mathrm{hr}$ and 0 to $5 \mathrm{~mm} / \mathrm{hr}$ respectively. EBLUS is not commonly practiced in acacia wooded grass land of Rift valley for which measurement is not done. Hence, the infiltration rate of soils in the acacia wooded grass land is not measured because of our focus was comparison of land use systems which are found in the same zone and the same soil type with EBLUS and the average value is presented in Table 6.

Sandy loam soil textural class has higher infiltration capacity than other textural classes followed by silt loam in all land use systems. High infiltration capacity is measured in the natural forest covered portion of the watershed followed by EBLUS. EBLUS improves the infiltration and water holding capacity of the soil by increasing the organic matter content of the soil through litter and pseudo stem cover falls and also the root fiber of 2 to 3 meters long away from the edge of the pseudo stem measured in the field that can enhance the void space of the soil to transmit rain water easily to the ground. The presence of wide leaves protects the direct impact 
of the rain drop (Kebede Wolka, et al, 2015) and permit more through fall which reduces the speed of the rain drop and it will give more time for rain water to infiltrate to the ground.

Table 6: Mean infiltration rate of land uses

\begin{tabular}{|c|c|c|c|c|c|}
\hline \multicolumn{5}{|c|}{ Mean Infiltration Rate (mm/Hour) } & \multirow{3}{*}{$\begin{array}{l}\text { Basic infiltration } \\
\text { rate ( } \mathbf{m m} / \text { hour) } \\
\text { (Oliver, Niels, Hogler, \& } \\
\text { Reinhard, 2006) }\end{array}$} \\
\hline \multirow[t]{2}{*}{ Land Use } & \multirow[t]{2}{*}{ Soil Texture } & \multicolumn{3}{|c|}{ Zone } & \\
\hline & & Upper zone & Middle zone & $\begin{array}{l}\text { Maen } \\
\text { infiltration } \\
\text { rate for LUSs }\end{array}$ & \\
\hline \multirow{4}{*}{$\begin{array}{l}\text { Cultivated } \\
\text { LUS }\end{array}$} & Sandy Loam & & 19.125 & \multirow{4}{*}{10.375} & 20 to 30 \\
\hline & Silt Loam & 12 & 13.9625 & & 10 to 20 \\
\hline & Clay Loam & 7.2125 & 5.825 & & 5 to 10 \\
\hline & Clay & & 4.125 & & 1 to 5 \\
\hline \multirow{4}{*}{$\begin{array}{l}\text { Built up \& } \\
\text { degraded LUS }\end{array}$} & Sandy Loam & & 8.75 & \multirow{4}{*}{7.0625} & 20 to 30 \\
\hline & Silt Loam & 7.0625 & 10 & & 10 to 20 \\
\hline & Clay Loam & & 5.5 & & 5 to 10 \\
\hline & Clay & & 4 & & 1 to 5 \\
\hline \multirow{4}{*}{$\begin{array}{l}\text { Grass land \& } \\
\text { planted forest } \\
\text { LUS }\end{array}$} & Sandy Loam & & 19.25 & \multirow{4}{*}{11.1875} & 20 to 30 \\
\hline & Silt Loam & 15.8625 & 9.95 & & 10 to 20 \\
\hline & Clay Loam & 8.6 & 7.9625 & & 5 to 10 \\
\hline & Clay & & 5.5 & & 1 to 5 \\
\hline \multirow[t]{4}{*}{ EBLUS } & Sandy Loam & & 22.55 & \multirow{4}{*}{12.8125} & 20 to 30 \\
\hline & Silt Loam & 12.625 & 17.025 & & 10 to 20 \\
\hline & Clay Loam & 10.875 & 9.375 & & 5 to 10 \\
\hline & Clay & & 4.425 & & 1 to 5 \\
\hline \multirow{4}{*}{$\begin{array}{l}\text { Natural } \\
\text { Forest LUS }\end{array}$} & Sandy Loam & & 22.625 & \multirow{4}{*}{12.9675} & 20 to 30 \\
\hline & Silt Loam & 15.25 & 15.5 & & 10 to 20 \\
\hline & Clay Loam & 9.625 & 10.3475 & & 5 to 10 \\
\hline & Clay & & 4.4575 & & 1 to 5 \\
\hline Average & & 11.0125 & 10.92625 & & \\
\hline
\end{tabular}

The Upper zone of the watershed has higher mean infiltration rate $(11.0125 \mathrm{~mm} / \mathrm{hr})$ than the Middle zone $(10.92625 \mathrm{~mm} / \mathrm{hr})$ of the watershed. The high mean infiltration rate at the upper zone shows the presence of more forest LUS and EBLUS than the middle zone of the watershed which enhances infiltration and water holding capacity of the soil. In the cultivated LUS, high 
rate of infiltration is recorded in upper zone of the watershed while middle zone has more infiltration rates in Grass LUS, forest LUS and EBLUS as shown in Figure 15, which is attributed to the high slope of upper zone that influences the carbon stock of the soil.

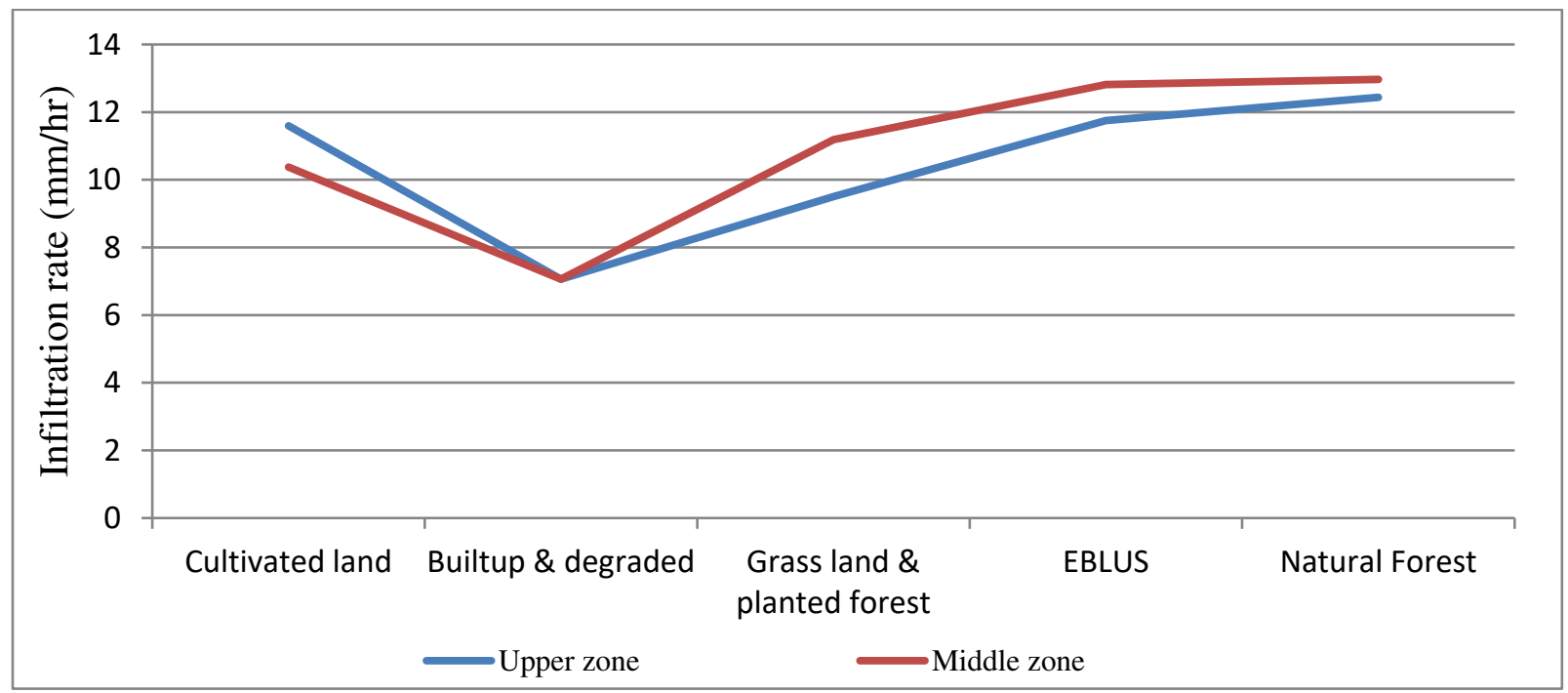

Figure 15: Vegetation zone based infiltration capacity of the soil $(\mathrm{mm} / \mathrm{hr})$

There is a significant difference between infiltration rates at different land use systems at $5 \%$ significance level $(\alpha=0.05)$ with a p-value of $0.0094(<\alpha)$ due to a low value in the Built-up \& degraded and cultivated LUS and a high value in Forests and EBLUS and a non-significance difference is observed between infiltration rates among vegetation zones with $p$-value of 0.443 $(>\alpha)$ as shown in Table 7.

Table 7: Analysis of variance (ANOVA)

\begin{tabular}{|l|c|r|c|c|c|c|}
\hline \multicolumn{1}{|c|}{ Source of Variation } & SS & df & MS & F & P-value & F crit \\
\hline Land use systems & 40.16427 & 4 & 10.04107 & 16.51739 & 0.009404 & 6.388233 \\
\hline Vegetation zone & 0.440475 & 1 & 0.440475 & 0.724574 & 0.442606 & 7.708647 \\
\hline Error & 2.431635 & 4 & 0.607909 & & & \\
\hline Total & 43.03638 & 9 & & & & \\
\hline & & & & & & \\
\hline
\end{tabular}


Therefore, a high mean infiltration rate in Forests and EBLUS show that there is an improvement in hydrological parameters for those land use systems to enhance water absorption to the ground water system. The improvement in infiltration capacity has a direct influence on water resources management. In addition, the increase in infiltration rate has a huge contribution in runoff reduction and alleviation of sedimentation problems in Meki river watershed.

\subsection{Curve number modeling result}

Soil Conservation Curve Number (SCS-CN) is an empirically derived relationship between location, land use, antecedent moisture conditions and runoff and it is used in many eventbased models to establish the initial soil moisture condition and the infiltration characteristics (Iliasse \& Adil, 2014). There is an inverse relationship between infiltration capacity and the runoff generation capacity of the area (A.R., H.A., \& S.H.R., 2010; Zehetner \& Miller, 2006; Zeiger \& Fohrer, 2009); hence the infiltration capacity of the soil is considered as one of the criteria to model the curve number of EBLUS.

Studies showed that organic matter influences $\mathrm{CN}$ and results in low surface runoff due to an increasing in soil infiltration capacity (A.R., H.A., \& S.H.R., 2010; Zehetner \& Miller, 2006; Zeiger \& Fohrer, 2009). According to Mesfin, et al (2017) and Barbora and Jaroslava (2014), compost improves and accelerated both the infiltration and water holding capacity of the soil for a longer period which in turn influences the $\mathrm{CN}$ of the watershed.

EBLUS exhibited a good carbon sequestration, which is equivalent to high-vegetation areas (Mesfin et al., 2017). Hence, Carbon stock considered as criteria to model the curve number of EBLUS next to the infiltration capacity of the soil as reported in Table 8. 
Table 8: Hydrologic Soil Group based curve number of different LULCs excluding Enset LULC (Iliasse and Adil, 2014; ERA, 2013)

\begin{tabular}{|c|c|c|c|c|c|c|c|}
\hline \multirow[b]{2}{*}{ Land Cover/Land Use } & \multicolumn{4}{|c|}{ Hydrologic Soil Group } & \multicolumn{3}{|c|}{ Parameters to develop the $\mathrm{CN}$ model } \\
\hline & A & B & C & D & $\begin{array}{l}\text { Carbon } \\
\text { (ton/yr) }\end{array}$ & 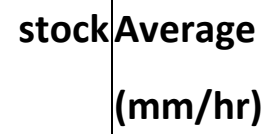 & Infiltration \\
\hline Open Water & 100 & 100 & 100 & 100 & 0 & 0 & \\
\hline Built-up, Medium Intensity LUS & 77 & 85 & 90 & 92 & 132 & 7.0625 & \\
\hline Natural Forest LUS & 36 & 60 & 73 & 79 & 45,714 & 12.9675 & \\
\hline Grasslands \& plantations LUS & 49 & 69 & 79 & 84 & 8350 & 11.1875 & \\
\hline Cultivated LUS & 67 & 78 & 85 & 89 & 19,950 & 10.375 & \\
\hline EBLUS & & & & & 77,286 & 12.8125 & \\
\hline
\end{tabular}

Therefore, considering the infiltration capacity of forest LUS, grass LUS, cultivated LUS and built-up LUS and their Carbon stock, the following formulas are derived to compute the curve number matrix of EBLUS relative to the other land use systems dominantly practiced in the study area.

$\mathrm{EA}=\frac{\sum_{i=1}^{n} E A i}{n}=\frac{C i(F A * I F+G A * I G+C A * I C+B A * I B)}{I E}+\frac{C S q(F A * S q F+G A * S q G+C A * S q C+B A * S q B)}{S q E}$ Eqn1 $\mathrm{EB}=\frac{\sum_{i=1}^{n} E B i}{n}=\frac{C i(F B * I F+G B * I G+C B * I C+B B * I B)}{I E}+\frac{C S q(F B * S q F+G B * S q G+C B * S q C+B B * S q B)}{S q E} \quad$ Eqn2 $\mathrm{EC}=\frac{\sum_{i=1}^{n} E C i}{n}=\frac{C i(F C * I F+G C * I G+C C * I C+B C * I B)}{I E}+\frac{C S q(F C * S q F+G C * S q G+C C * S q C+B C * S q B)}{S q E} \quad$ Eqn3 $\mathrm{ED}=\frac{\sum_{i=1}^{n} E D i}{n}=\frac{C i(F D * I F+G D * I G+C D * I C+B D * I B)}{I E}+\frac{C S q(F D * S q F+G D * S q G+C D * S q C+B D * S q B)}{S q E} \quad$ Eqn4 Where;

$E A, E B, E C$ and $E D$ are CN of EBLUS for HSG of $A, B, C$ and $D$ respectively 
FA, FB, FC and FD are CN of Forest LUS for HSG of $A, B, C$ and D respectively

GA, GB, GC and GD are CN of Grass LUS for HSG of A, B, C and D respectively

CA, CB, CC and CD are CN of Cultivated LUS for HSG of $A, B, C$ and D respectively

$B A, B B, B C$ and $B D$ are $C N$ of Built-up LUS for HSG of $A, B, C$ and $D$ respectively

IE, IF, IG, IC and IB are infiltration capacity of EBLUS, Forest, Grass, Cultivated and Built-up LUSs respectively.

$\mathrm{SqE}, \mathrm{SqF}, \mathrm{SqG}, \mathrm{SqC}$ and SqB are Carbon stock of EBLUS, Forest, Grass, Cultivated and Built-up land use systems respectively.

$\mathrm{Ci}$ and CSq are coefficients for the relative influence of infiltration capacity and Carbon stock on curve number of land use systems respectively at $85 \%$ to $15 \%$ proportion.

Accordingly, the curve numbers are generated for EBLUS for each hydrologic soil group with their respective infiltration capacity and Carbon stock relative to other LUSs for which curve number is encoded and presented in Table 9. Carbon stock is modified by growth period and energy production of those LUSs. Hence, infiltration capacity of the soil powers $85 \%$ of the curve number of LUSs while $15 \%$ of the curve numbers of LUSs are influenced by carbon stock which is computed.

Table 9: Curve number of EBLUS

\begin{tabular}{|c|l|l|l|l|}
\hline Curve number & \multicolumn{4}{l|}{ Hydrologic Soil Group (HSG) } \\
\hline CN of EBLUS due to Infiltration capacity & $\mathrm{A}$ & $\mathrm{B}$ & $\mathrm{C}$ & $\mathrm{D}$ \\
\hline $\mathrm{EI} 1=\frac{B A * I B}{I E}$ & 42.44 & 46.854 & 49.61 & 50.712 \\
\hline $\mathrm{EI} 2=\frac{F A * I F}{I E}$ & 36.44 & 60.73 & 73.88 & 79.96 \\
\hline $\mathrm{EI} 3=\frac{G A * I G}{I E}$ & 42.79 & 60.25 & 68.98 & 73.35 \\
\hline $\mathrm{EI} 4=\frac{C A * I C}{I E}$ & 54.25 & 63.16 & 68.83 & 72.068 \\
\hline
\end{tabular}




\begin{tabular}{|c|c|c|c|c|}
\hline CN of EBLUS due to Carbon stock & A & $\mathrm{B}$ & C & $\mathrm{D}$ \\
\hline $\mathrm{ESq} 1=\frac{B A * S q B}{S q E}$ & 0.13 & 0.145 & 0.154 & 0.16 \\
\hline $\mathrm{ESq} 2=\frac{F A * S q F}{S q E}$ & 21.294 & 35.49 & 43.18 & 46.73 \\
\hline $\mathrm{ESq} 3=\frac{G A * S q G}{S q E}$ & 5.294 & 7.455 & 8.54 & 9.075 \\
\hline $\mathrm{ESq} 4=\frac{C A * S q C}{S q E}$ & 17.295 & 20.13 & 21.94 & 22.97 \\
\hline Cumulative $\mathrm{CN}$ of EBLUS for different HSG & A & $B$ & $\mathrm{C}$ & $\mathrm{D}$ \\
\hline $\mathrm{E}=\frac{0.85 * \sum_{i=1}^{4} E I i+0.15 * \sum_{i=1}^{4} E S q i}{4}$ & 39 & 51.5 & 58.3 & 61.6 \\
\hline
\end{tabular}

Therefore, finally the general formula developed for EBLUS is given as: $\mathrm{E}=\frac{0.85 * \sum_{i=1}^{n} E I i+0.15 * \sum_{i=1}^{n} E S q i}{n}$

Alemu's formula

\section{Where:}

Eli $=$ Infiltration based Curve number of EBLUS relative to i LUS

ESqi $=$ Carbon stock based Curve number of EBLUS relative to i LUS

Curve number matrix is computed for EBLUS using the model as 39, 51.5, 58.3 and 61.6 for HSG of $A, B, C$ and $D$ respectively. Therefore, the new lookup table for all land use systems including EBLUS is prepared as shown in Table 10 and fed to HEC-GEO-HMS together with that of the union of LUS and soil information in order to generate the curve number grid.

Table 10: Hydrologic Soil Group based curve number of different LUSs including EBLUS

\begin{tabular}{|l|c|c|c|c|}
\hline & \multicolumn{4}{|l|}{ Hydrologic Soil Group } \\
\hline Land Cover/Land Use & A & B & C & D \\
\hline Open Water & 100 & 100 & 100 & 100 \\
\hline Builtup, Medium Intensity & 77 & 85 & 90 & 92 \\
\hline Natural Forest & 36 & 60 & 73 & 79 \\
\hline Grasslands (Pasture) \& plantation lands & 49 & 69 & 79 & 84 \\
\hline Cultivated land & 67 & 78 & 85 & 89 \\
\hline
\end{tabular}




\begin{tabular}{|l|l|l|l|l|}
\hline EBLULC & 39 & 51.5 & 58.3 & 61.6 \\
\hline
\end{tabular}

Hence, the new $\mathrm{CN}$ matrix of the Meki river watershed is generated from the new lookup table including EBLUS and mapped as shown in Figure 16. This CN grid can be used in different models of rainfall-runoff modeling purposes and also researchers and runoff flow simulators.

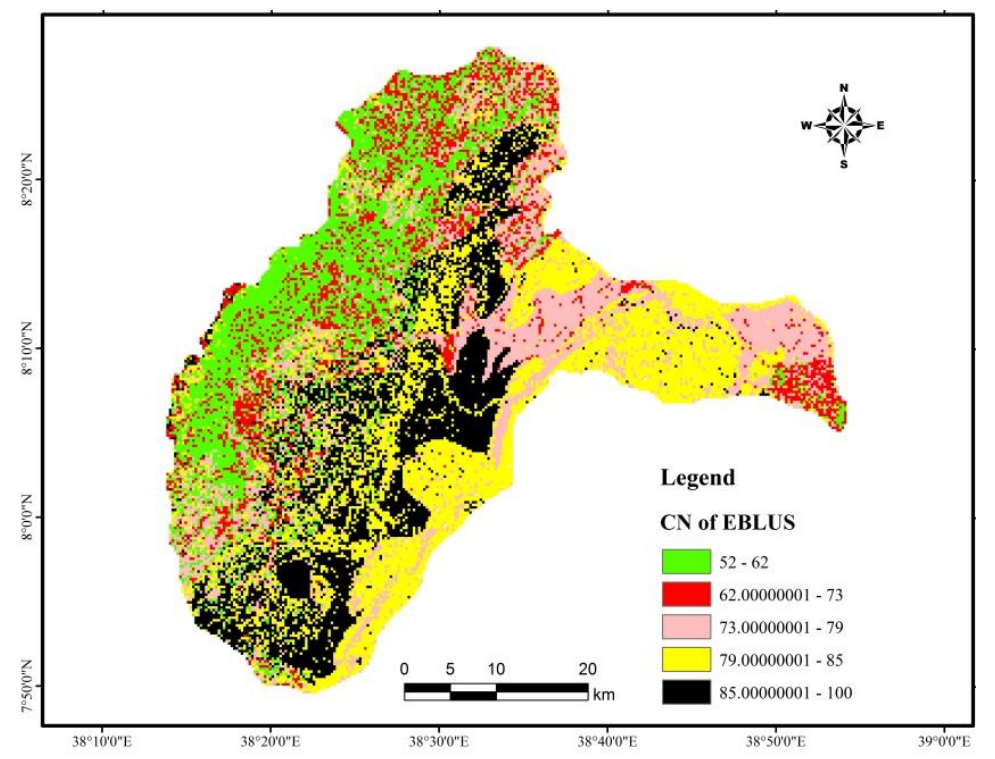

Figure 16: Average soil loss from sub-watersheds with respect to Rift valley limit

\subsection{Zone and sub-watershed based $\mathrm{CN}$ determination}

$\mathrm{CN}$ of EBLUS is evaluated for two enset growing zones of Meki river watershed and the mean values of the upper zone is less than the middle one due to the high proportion of forest and EBLUS in the upper zone of the watershed as shown in Table 11.

Table 11: $\mathrm{CN}$ of zones of Meki river watershed

\begin{tabular}{|l|l|l|}
\hline Zones & Upper & Middle \\
\hline Minimum & 52 & 52 \\
\hline
\end{tabular}




\begin{tabular}{|l|l|l|}
\hline Mean & 72.78 & 83.27 \\
\hline Maximum & 100 & 92 \\
\hline
\end{tabular}

Almost all upper zone Sub-watersheds except U9 have a mean $\mathrm{CN}$ value of less than 80 while almost all middle zone Sub-watersheds have a mean $\mathrm{CN}$ of more than 80 except $\mathrm{M} 1$ and $\mathrm{M} 3$ as shown in Figure 17.

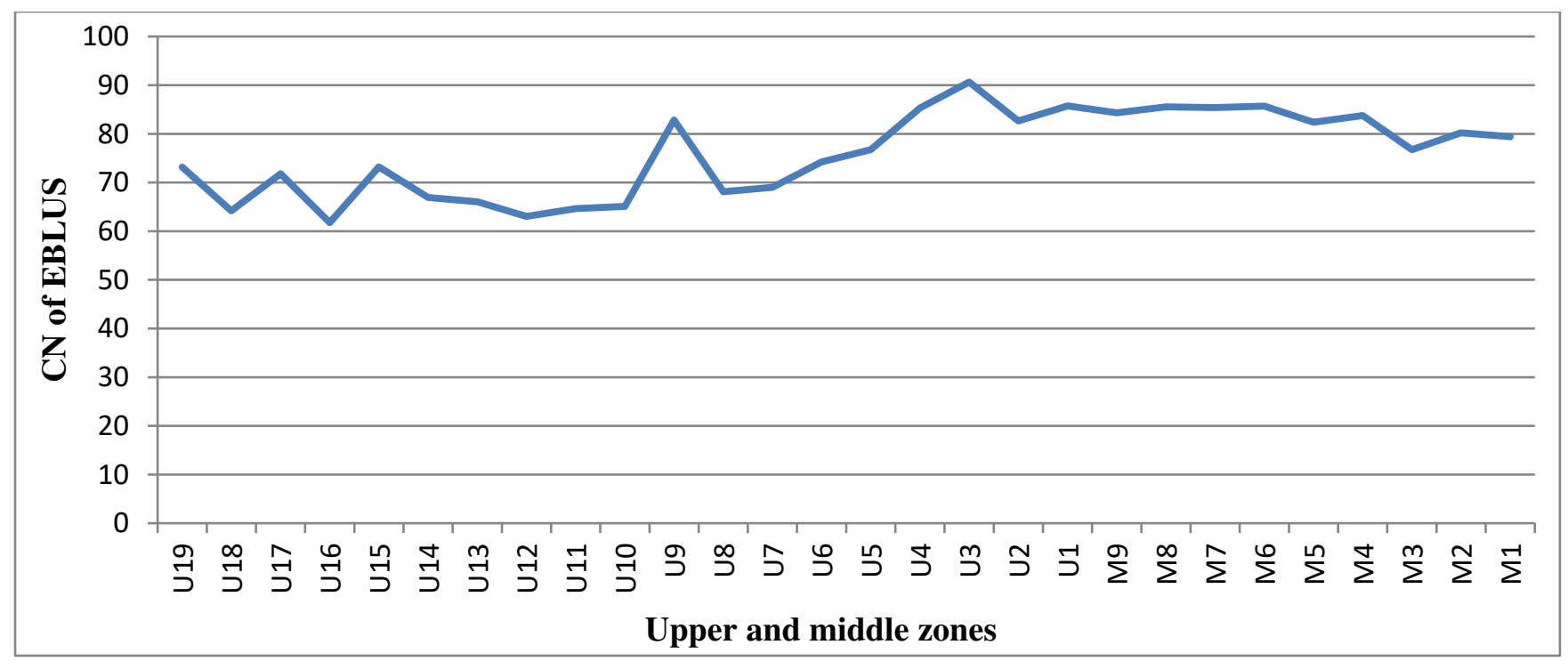

Figure 17: Curve number of EBLUS in the upper and middle zones

\subsection{Scenarios on mean $\mathrm{CN}$ of Meki river watershed with respect to EBLUS}

Meki river watershed has a mean $\mathrm{CN}$ of 78.21 considering EBLUS as it has its own CN matrix while a mean CN of 81.72 by considering EBLUS as cultivated LUS as shown in the Table 12 below.

Table 12: Area coverage and average $\mathrm{CN}$ of land uses

\begin{tabular}{|l|l|l|l|l|}
\hline LU & Area $\left(\mathrm{km}^{2}\right)$ & Mean CN, EBLUS as & Mean CN, EBLUS as a & Area (\%) \\
\hline
\end{tabular}




\begin{tabular}{|l|c|c|c|c|}
\hline & & separate LUS & cultivated LUS & \\
\hline EBLUS & 247.59 & 56.15 & 77.26 & 10.65 \\
\hline Cultivated LUS & 964.05 & 77.26 & 77.26 & 41.46 \\
\hline Bush and Chat LUS & 595.59 & 76.87 & 76.87 & 25.61 \\
\hline Forest and plantation LUS & 328.98 & 69.1 & 69.06 & 14.15 \\
\hline Urban (Built up) LUS & 171.69 & 89.86 & 89.86 & 7.38 \\
\hline Water bodies & 17.4 & 100 & 100 & 0.75 \\
\hline
\end{tabular}

The mean $\mathrm{CN}$ of Meki river watershed considering and without considering EBLUS are 78.21 and 81.72 respectively, hence, the sorpitivity and initial abstraction of the watershed decreases as $\mathrm{CN}$ increases as shown in Table 13.

Table 13: Initial abstraction and soil retention in millimeters

\begin{tabular}{|l|l|l|l|l|}
\hline & $\mathrm{CN}$ & Sorpitivity $=\mathrm{S}=\frac{25400}{\mathrm{CN}}-254$ & $\begin{array}{l}\text { Initial abstraction (la) } \\
0.2 \mathrm{~S}\end{array}$ & \\
\hline With & $\begin{array}{l}78.2066 \\
7\end{array}$ & 70.7804961 & 14.1560992 & $0.8 \mathrm{~S}$ \\
\hline WO & $\begin{array}{l}81.7181 \\
3\end{array}$ & 56.8245439 & 11.3649088 & 56.6243969 \\
\hline
\end{tabular}

The CN of EBLUS is computed with respect to other LUSs. According to Chow et al, (1988) and Merwade (2012), the precipitation excess is a function of cumulative precipitation, soil type, land use systems and antecedent moisture. Considering the initial loss and the potential maximum retention, the precipitation excess can be calculated; the maximum retention and the basin characteristics are related through the curve number. The standard SCS curve number method is based on the following relationship between rainfall depth, P, and runoff depth, Q 
(USDA, 1986; Schulze et al., 1992) which can easily be simulated using HEC-HMS using the CN as an input.

For the annual daily average rainfall of $50 \mathrm{~mm}$ for Meki river watershed (ENMA, 2017), the runoff considering and without considering EBLUS is computed respectively as:

$\mathrm{Q} 1=\frac{(\mathrm{P}-0.2 \mathrm{~S} 1)^{2}}{(\mathrm{P}+0.8 \mathrm{~S} 1)}=\frac{(50-14.156)^{2}}{(50+56.6244)}=\frac{1284.792336}{106.6244}=12.05 \mathrm{~mm}$ and $\quad$ (Chow et al, 1988)

$\mathrm{Q} 2=\frac{(\mathrm{P}-0.2 \mathrm{~S} 2)^{2}}{(\mathrm{P}+0.8 \mathrm{~S} 2)}=\frac{(50-11.365)^{2}}{(50+45.46)}=\frac{1492.663225}{95.46}=15.6366 \mathrm{~mm}$

Where: $Q$ is surface runoff $(\mathrm{mm}), P$ is precipitation $(\mathrm{mm}), S$ is the soil retention (Sorpitivity) $(\mathrm{mm})$ and la is initial abstraction or initial loss $(\mathrm{mm})$ and $\mathrm{CN}$ is curve number

Hence a difference of runoff occurs due to consideration of EBLUS by $3.59 \mathrm{~mm}$ which can be cumulate to a huge volume of runoff $\left(8340916 \mathrm{~m}^{3}\right)$ from the whole area of Meki river watershed which can be a sign post for the improvement of the hydrological characteristics of the watershed by increasing the infiltration capacity of the soil.

\section{Conclusion\& Recommendation}

\section{Conclusion}

Meki river watershed is dominantly covered by cultivated LUS (41.5\%) followed by Bush and Chat LUSs (25.6\%). EBLUS comprises about $10.65 \%$ of the watershed while Forest and plantations LUSs cover (14.14\%) while urban and built up LUSs covers $7.4 \%$ with minimal portion is covered by water bodies including wetland (0.75\%). Uppermost part of the Meki river watershed is covered by Erica, Enset and natural forest land use systems, while the middle and lower altitudes of the watershed is dominantly covered by agricultural LUSs. 
The $\mathrm{CN}$ grid in a Meki river watershed can be used as an input for different research purposes concerning direct runoff generation capacity of the area. There is an improvement of average $\mathrm{CN}$ from 81.72 to 78.21 for the whole watershed. A significant volume of water $\left(8340916 \mathrm{~m}^{3}\right)$ is infiltrated due to the presence of EBLUS in the watershed.

Therefore, a high mean infiltration rate in Forests and EBLUS shows that there is an improvement in hydrological parameters for those LUSs to enhance water absorption into the ground water system. The improvement in infiltration capacity has a direct influence on water resources management. In addition, the increase in infiltration rate has a huge contribution in runoff reduction and alleviation of sedimentation problems in the Meki river watershed.

\title{
Recommendation
}

A significant CN reduction due to EBLUS shows there will be an improvement in the hydrological characteristics of the watershed by increasing the infiltration capacity of the soil and also by increasing the canopy cover of the area. Hence, increasing the coverage of EBLUS can reduce the $\mathrm{CN}$ and runoff volume which could be the cause of flooding in different parts of the watershed and also protect Lake Ziway against sedimentation.

Therefore, creating separate land use policy to EBLUS and incorporating other fruit as an agroforestry to it will create harmony to the existing ecology. The extension program has to be initiated to the expansive production and processing of EBLUS which can help the production of sufficient inputs to the industries to be established in the area.

\author{
Abbreviations \\ DEM \\ Digital Elevation Model \\ EBLUS Enset-Based Land Use System \\ EGSIA Ethiopian geospatial information agency \\ ENMA Ethiopian National Meteorological Agency
}




$\begin{array}{ll}\text { ERA } & \text { Ethiopian Road Authority } \\ \text { ERDAS } & \text { Earth Resources Data Acquisition System } \\ \text { GIS } & \text { Geographical Information System } \\ \text { GPS } & \text { Geographical Positioning System } \\ \text { HEC-GEO-HMS } & \text { Hydrologic Engineering Center's Geospatial Hydrologic Modeling System } \\ \text { HEC-HMS } & \text { Hydrologic Engineering Center's Hydrologic Modeling System } \\ \text { HSG } & \text { Hydrologic Soil Group } \\ \text { HWSD } & \text { Harmonized World Soil Data } \\ \text { LULCC } & \text { Land Uses and Land Cover Change } \\ \text { LUSS } & \text { Land use systems } \\ \text { m.a.s.I. } & \text { Meter above Sea Level } \\ \text { MOWIE } & \text { Ministry of Water, Irrigation and Energy } \\ \text { SCS-CN } & \text { Soil Conservation Services Curve Number }\end{array}$

\section{DECLARATION}

Originality of work

We assure that, this paper is the original work and have not been presented for a degree in any other university, and all sources of material used for this paper have been duly acknowledged.

Ethics approval and consent to participate

'Not applicable'

Consent for publication 
'Not applicable'

Availability of data and material

Data are acquired from Ministry of Water, Irrigation \& Electricity (MOWIE) of Ethiopia for flow data, Ethiopian Meteorological Agency (EMA) for meteorological data, Ethiopian Central Statistical Agency (ECSA) for population data, Ethiopian Geospatial \& Mapping Agency (EGMA) for Satellite images and topo-maps, Satellite images from USGS earth explorer and field materials acquired from Ethiopian Institute of Water Resources (EIWR) in Addis Ababa University.

\section{Competing interests}

"The authors declare that they have no competing interests"

\section{Funding}

Our research is funded by Addis Ababa University (Student grant and thematic research fund)

\section{Authors' contributions}

Authors in this article made substantial contributions to the conception and design of the work; the acquisition, analysis and interpretation of data and finally have drafted the work or substantively revised it together and the authors read and approved the final manuscript.

\section{Acknowledgements}

Thanks to God for being with us. We gratefully acknowledge the contributions of Dr Feleke Zewge and Dr. Bikila from Addis Ababa University, College of Natural and Computational 
Sciences and Mr Mamo Kassegn from Ethiopian institute of water resources. We want to express our greatest appreciation to Ministry of Water, Irrigation and Electricity (MOWIE) of Ethiopia and National Meteorological Agencies (NMA), Ethiopian Central Statistical Agency (ECSA), Ethiopian Geospatial \& Mapping Agency (EGMA) and Ethiopian Institute of Water Resources (EIWR) of Addis Ababa University for providing necessary data, materials, equipment and information for this study.

This research was also supported in part by thematic research fund of Addis Ababa University, College of Natural and Computational Sciences, Department of Biology and also supported by student fund from Ethiopian Institute of Water Resources (EIWR) in Addis Ababa University. 


\section{Reference}

A. R. , V., H. A. , B., \& S. H. R. , S. (2010). Modeling relationship between runoff and soil properties in dry-farming lands, NW Iran. Hydrology and Earth System Sciences (HESS), 7, 2577-2607.

A., P. N., B., J. W., \& J., D. M. (2011). Evaluating the impacts of land use changes on hydrologic responses in the agricultural regions of Michigan and Wisconsin.

A.O.Ibeje, J. a. (2018). Impact of land use on infiltration. World journal of Engineering Research and Technology, 4 (6), $95-102$.

Admasu Tsegaye 1 and P.C.Struik2 (2003). Growth, radiation use efficiency and yield potential of enset (Ensete ventricosum) at different sites in southern Ethiopia. Ann. appl. Biol., $142,71-81$.

Admasu, T. (2007). Effect of repetitive transplanting \& leafe pruning on growth and dry matter partitioning of Enset. Agronomy, 6(1), 45-52.

Alemu Beyene, Sebsebe Demisew, Mekuria Argaw, Azage Gebreyohannes (2020). Enset-Based land use land cover change detection and its impact on soil erosion in Meki river watershed, Western Lake Ziway Sub-Basin, Central Rift Valley of Ethiopia, International Journal of Environmental Systems Research / Journal code: 40068-020-00198-x_ArticleMs Code: ENSR-D-20-00048.

Anita S., Haile B., Tesfaye S., Abebe Y., Amaldegn A. and Tabogie E. (1996). Enset Farming Systems in Southern Region, Ethiopia. Report on a Rapid Rural Appraisal in Gurage, 
Hadiya and Sidama Zones, University of Florida. Deutsche Gesellschaft for Technische Zusammenarbeit (GTZ), 83.

Barbora, B., \& Jaroslava, B. (2014). Effect of various compost doses on the soil infiltration capacity. 62.

BRIDGE, W. P. (1992). The lesion nematode pratylenchus goodeyi, an important pest of Ensete in Ethiopia. Tropical pest management, 38(3), 325-326.

Burch, G., Bath, R., Moore, I., \& O’Loughlin, E. (1987). A comparative hydrological behavior of forested and cleared catchments in south eastern Australia. Journal of Hydrology, 90, 19-42.

Chow, V. T., R.Maidment, D., \& Mays, L. W. (1988). APPLIED HYDROLOGY. New York St. Louis San Francisco Auckland Bogota Caracas Lisbon London Madrid Mexico City Milan Montreal New Delhi San Juan Singapore Sydney Tokyo Toronto: McGraw-Hill, Inc.

Ethiopia Minister of Water and Energy (2013). Strategic agenda for adaptation to urban watermediated impacts of climate change in Addis Ababa, Federal Democratic Republic of Ethiopia.

Iliasse Khaddor and AdilHafidiAlaoui (2014). Production of a Curve Number map for Hydrological simulation - Case study: Kalaya Watershed located in Northern Morocco. International Journal of Innovation and Applied Studies. ISSN 2028-9324 Vol. 9 No. 4 Dec. 2014, pp. 1691-1699 (C) 2014 Innovative Space of Scientific Research Journals http://www.ijias.issr-journals.org/

Elfert , S., \& Bormann, H. (2010). Simulated impact of past and possible future land use changes on the hydrological response of the Northern German lowland 'Hunte' catchment. J HYDROL, 383, 245- 255. 
Elias, A. A. (2011). Soil Nutrient Evaluation under Different Land Use Types in the Smallholder Farming Systems of Jimma Zone, Ethiopia. International Journal of Agricultural Research, 6(9), 707-713.

ENMA (2017). Ethiopian National Meteorological Agency data analysis, Addis Ababa, Ethiopia Ethiopian Road Authority (ERA) (2013). Drainage Design Manual, Addis Ababa, Ethiopia.

Feddema, J., Oleson, K., Bonan, G., Mearns, L., Buja, L., Meehl, G., et al. (2005). The importance of land-cover change in simulating future climates. SCIENCE, 310(5754), 1674-1678.

Ghaffari, G., Keesstra, S., Ghodousi, J., \& Ahmadi, H. (2010). SWAT-simulated hydrological impact of land-use change in the Zanjanrood Basin, Northwest Iran. HYDROL PROCESS, 24(7), 892-903.

James Harrison 1, K. A. (2014). A Draft Genome Sequence for Ensete ventricosum, the DroughtTolerant "Tree Against Hunger”. Agronomy, 4, 13-33.

Jerzy, R., Anna , R.-P., \& Jan , R. (2014). The Effect of Land Use Change on Transformation of Relief and Modification of Soils in Undulating Loess Area of East Poland. Scientific World Journal, 2014(341804).

Kebede Wolka, Habitamu Tadesse, Efrem Garedew and Fantaw Yimer (2015). Soil erosion risk assessment in the Chaleleka wetland watershed, Central Rift Valley of Ethiopia, Environmental Systems Research (2015) 4:5, DOI 10.1186/s40068-015-0030-5.

M. Fleming and T. Brauer (2018). Hydrologic Modeling System HEC-HMS Quick Start Guide, US Army Corps of Engineers, Institute of Water Resources, Hydrologic Engineering Center, 609 Second Street, Davis CA 95616-4687. 
Mbow, C., Van Noordwijk, M., Luedeling, E., Neufeldt, H., Minang, A., \& Kowero, G. (2014). Agroforestry solutions to address food security and climate change challenges in Africa. Curr. Opin. Environ. Sustain. 6:61-67. https://doi.org/10.1016/.

Merwade, V. (2012). Creating SCS Curve Number Grid using HEC-GeoHMS. School of Civil Engineering, Purdue University. vmerwade@purdue.edu, 1-26.

Mesfin, S., Christine, F., \& Kumlachew, Y. (2018). Plant diversity analysis for conservation of Afromontane vegetation in socio-ecological mountain landscape of Gurage, South Central Ethiopia. International Journal of Biodiversity and Conservation, 10(4), 161-171.

Mesfin, S., Osamu, S., Christine, F., \& Kumelachew, Y. (2017). Quantification and mapping of the supply of and demand for carbon storage and sequestration service in woody biomass and soil to mitigate climate change in the socio-ecological environment table 5 of pp 349.

MOWE (2013). Strategic agenda for adaptation to urban water-mediated impacts of climate change in Addis Ababa, Federal Democratic Republic of Ethiopia. Addis Ababa.

Nyssen, J., Habtamu , T., Mulugeta, L., Amanuel, Z., Nigussie , H., \& Mitiku , H. (2008). Spatial and temporal variation of soil organic carbon stocks in a lake retreat area of the Ethiopian Rift Valley. Geoderma, 146, 261-268.

Okirya Martin, Albert Rugumayo and Janka Ovcharovichova (2012). Application of Hec-Hms/Ras and GIS Tools in Flood Modeling: A Case Study for River Sironko, UGANDA. GLOBAL Journal of engineering, design \& technology. 
Oliver B., Niels A. W., Hogler F., and Reinhard F. H. (2006). Water infiltration and hydraulic conductivity in sandy cambisols: impacts of forest transformation on soil hydrological properties.

Oliver, B., Niels, A. W., Hogler, F., \& Reinhard, F. H. (2006). Water infiltration and hydraulic conductivity in sandy cambisols: impacts of forest transformation on soil hydrological properties.

Qiu, Y., Jia, Y., Zhao, J., Wang, X., Bennett, J., \& Zhou, Z. (2010). Valuation of flood reductions in the Yellow River Basin under land use change. J WATER RES PL-ASCE, 136(1), 106-115.

Remo, J., Pinter, N., \& Heine, R. (2010). The use of retro- and scenario-modeling to assess effects of $100+$ years river of engineering and land-cover change on Middle and Lower Mississippi River flood stages. J HYDROL, 376(3-4), 403-416.

Schilling, K., Jha, M., Zhang, Y., Gassman, P., \& Wolter, C. (2008). Impact of land use and land cover change on the water balance of a large agricultural watershed: Historical effects and future directions. WATER RESOUR RES 44, doi:10.1029/2007WR006644.

Shiferaw Feleke, R. L. (2003). Determinants of Food Security in Southern Ethiopia . American Agricultural Economics Association Meetings in Montreal, Canada, 1-29.

Tilahun A. \& Robert D. (2006). Improved Decision-Making for Achieving Triple Benefits of Food Security, Income and Environmental Services through Modeling Cropping Systems in the Ethiopian Highlands. African Highlands Initiative (AHI) working paper no. 20.

Tu, J. (2009). Combined impact of climate and land use changes on stream flow and water quality in eastern Massachusetts, USA. J HYDROL, 379, 268-283. 
Uloro Y. \& Mengel K. (2014). Response of Enset (Ensetventricosum W.) to mineral fertilizers in southwest Ethiopia,. SUdanlage 35390 Giessen, Germany: Institute of Plant Nutrition of the Justus Liebig University.

United States Department of Agriculture, Natural Resources Conservation Service (USDA-NRCS) (1986). "Urban Hydrology for Small Watersheds"; Technical Release 55, United States Department of Agriculture, Natural Resources Conservation Services, Conservation Engineering Division, Washington, DC, USA.

Ward, P., Renssen, H., Aerts, J., van Balen, R., \& Vandenberghe, J. (2008). Strong increases in flood frequency and discharge of the River Meuse over the late Holocene: impacts of long-term anthropogenic land use change and climate variability. HYDROL EARTH SYST SC., 12(1), 159-175.

Yimer, I. M. (2008). Effects of different land use types on infiltration capacity in a catchment in the highlands of Ethiopia. Soil Use and Management, 24, 344-349.

Yirmaga, M. T. (2013). Improving the Indigenous Processing of Kocho, an Ethiopian Traditional Fermented Food. Nutrition \& Food Sciences, 3(1), 1-6.

Zehetner, F., \& Miller, W. (2006). Erodibility and runoff-infiltration characteristics of volcanic ash soils along an altitudinal climosequence in the Ecuadorian Andes, Catena. Catena, 65, 201-213.

Zeiger, M., \& Fohrer, N. (2009). Impact of organic farming systems on runoff formation processes-A long-term sequential rainfall experiment, Soil Till. Res. Soil Tillage, 102, 4554. 
Figures

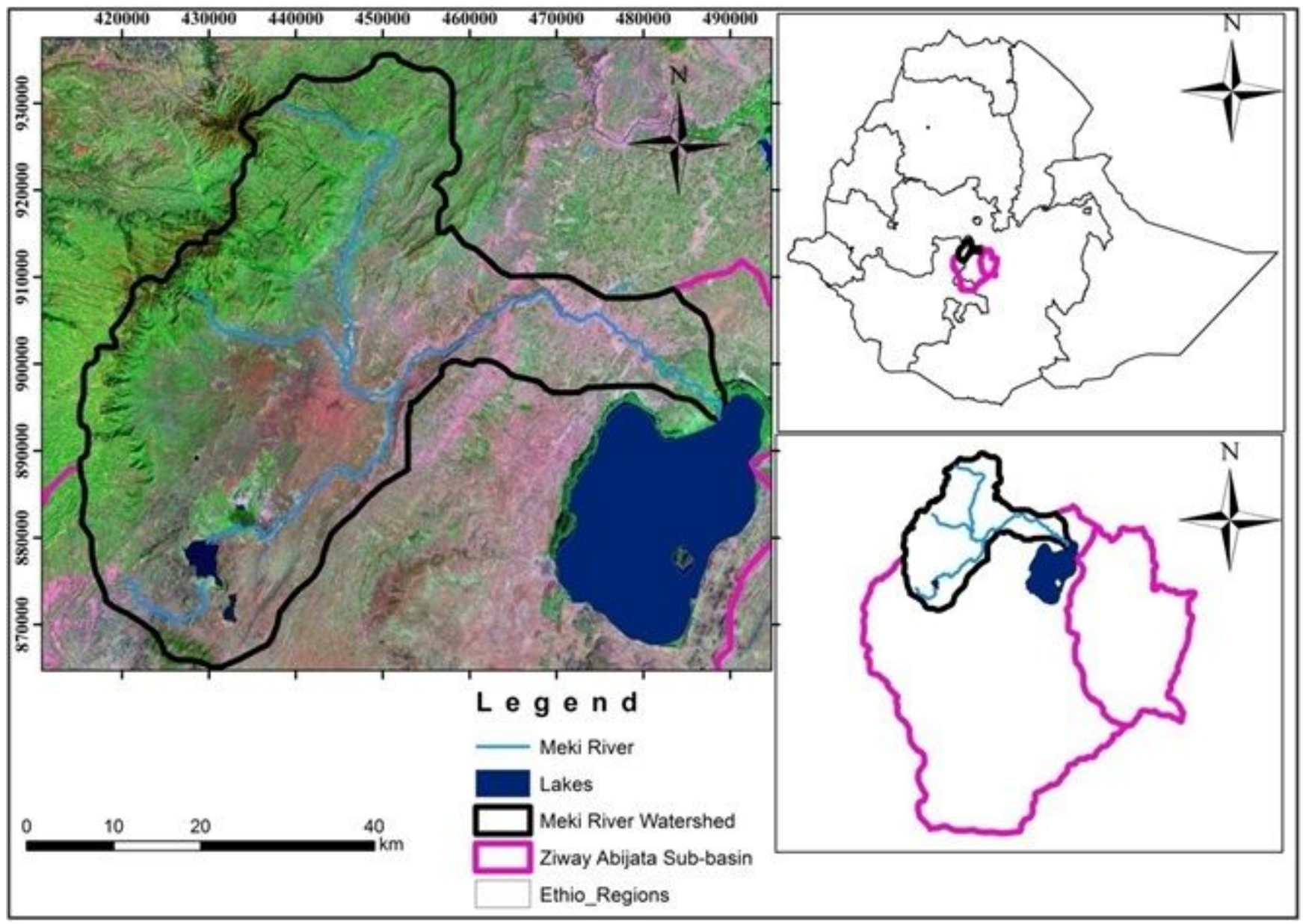

Figure 1

Study area map 


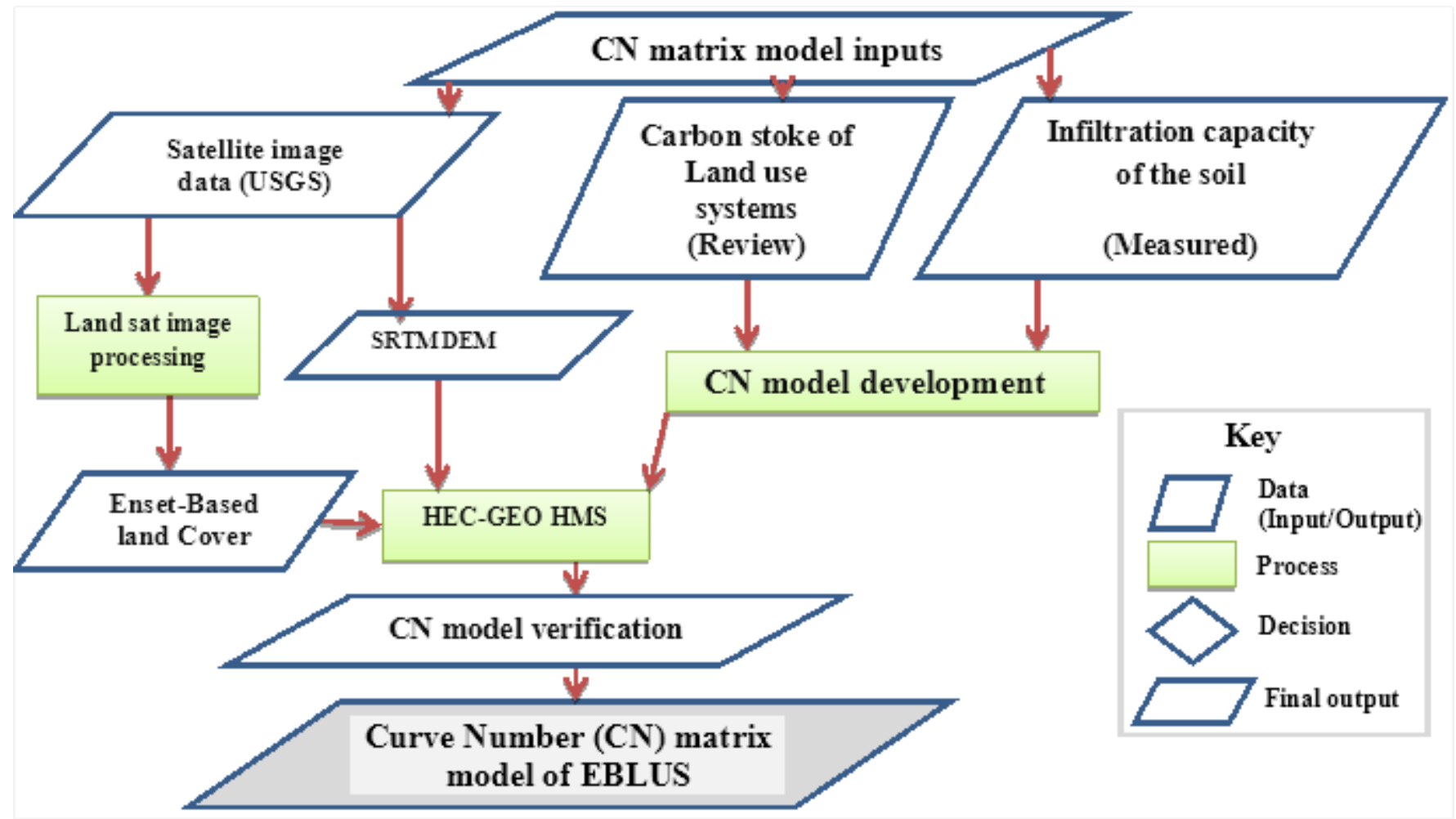

Figure 2

$\mathrm{CN}$ matrix model flow diagram 

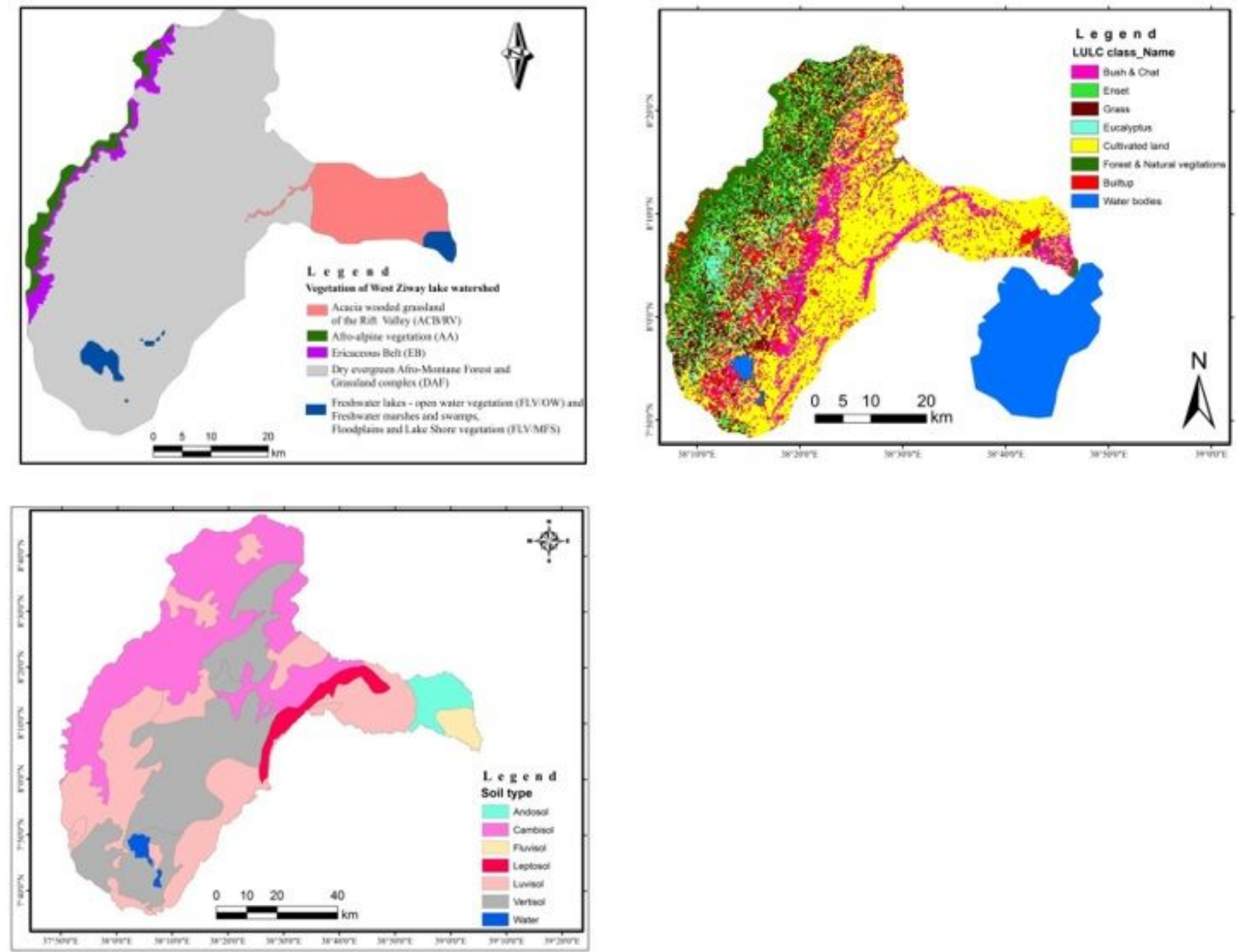

Figure 3

Dominant Vegetation zone, Land cover \& soil type maps of the study area 

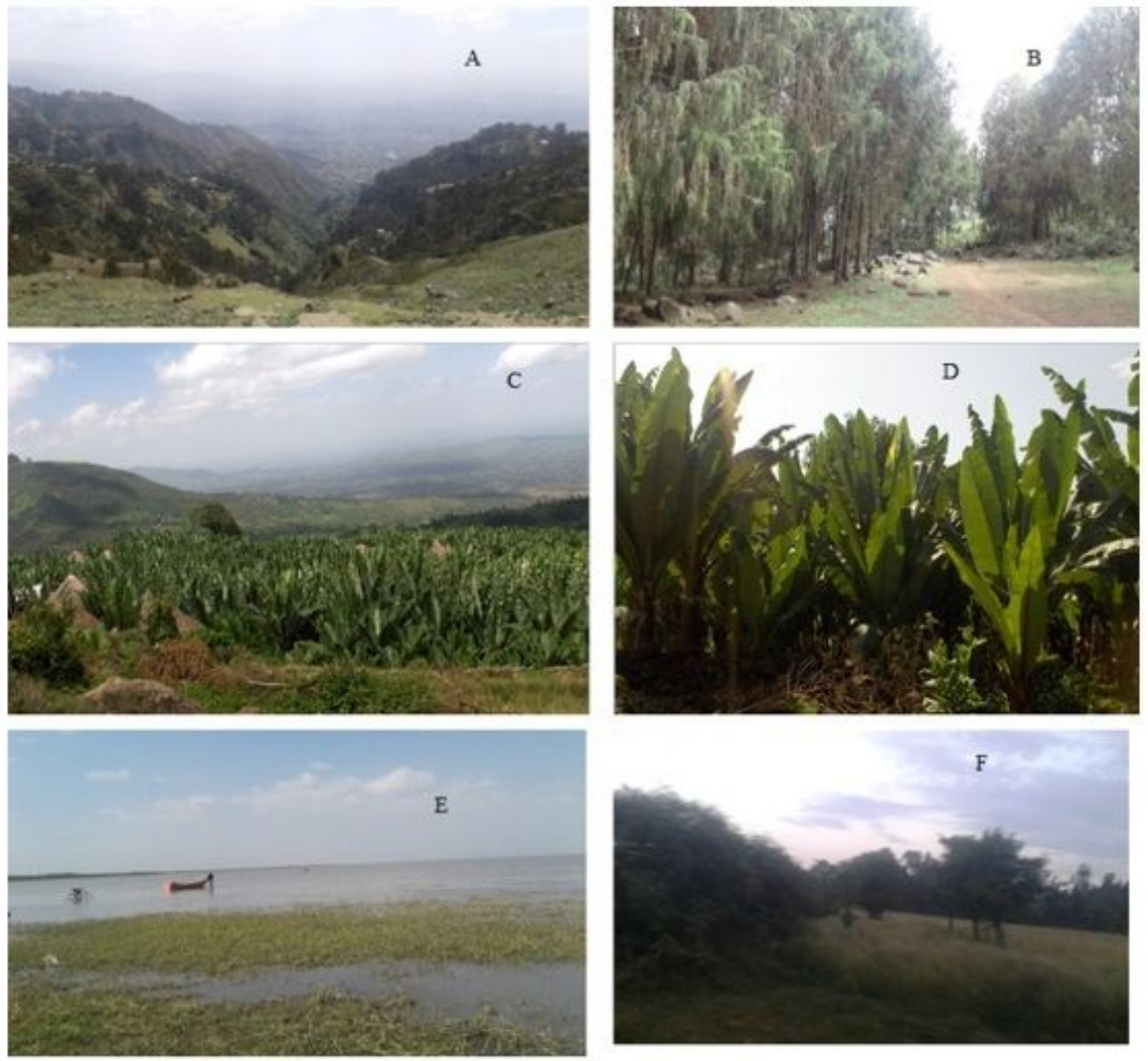

\section{Figure 4}

Vegetation zone verification assessment $\mathrm{A}=$ Divide line at western end of the watershed where more than half part of the watershed is visible (Silti zone) B \& F = Western upper part of Meskan woreda (Yewutin \& Yetebon respectively) $C=$ Found around Eastern Meskan woreda and Western Sodo woreda $D=$ Scene at Chohamba Meskan woreda $\mathrm{E}=$ Conversion from lake to wetland (Lake Ziway) 


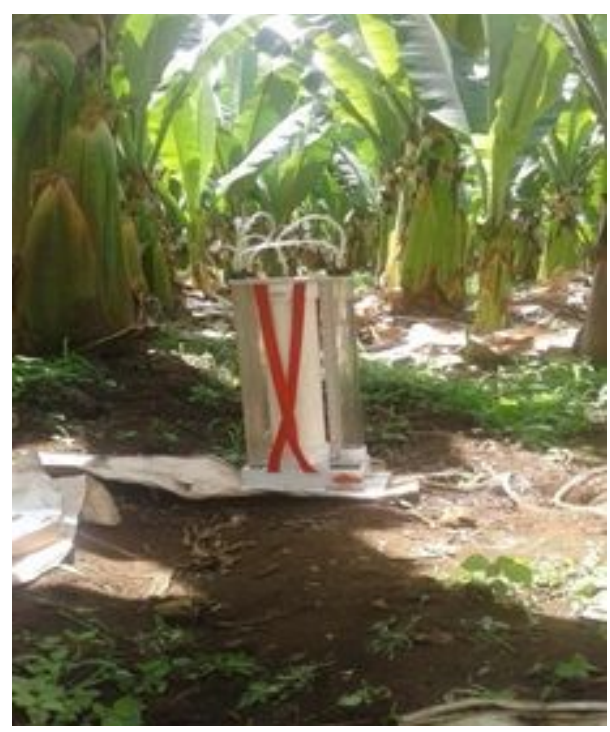

Figure 5

Amozi-meter infiltration measurement of EBLUS

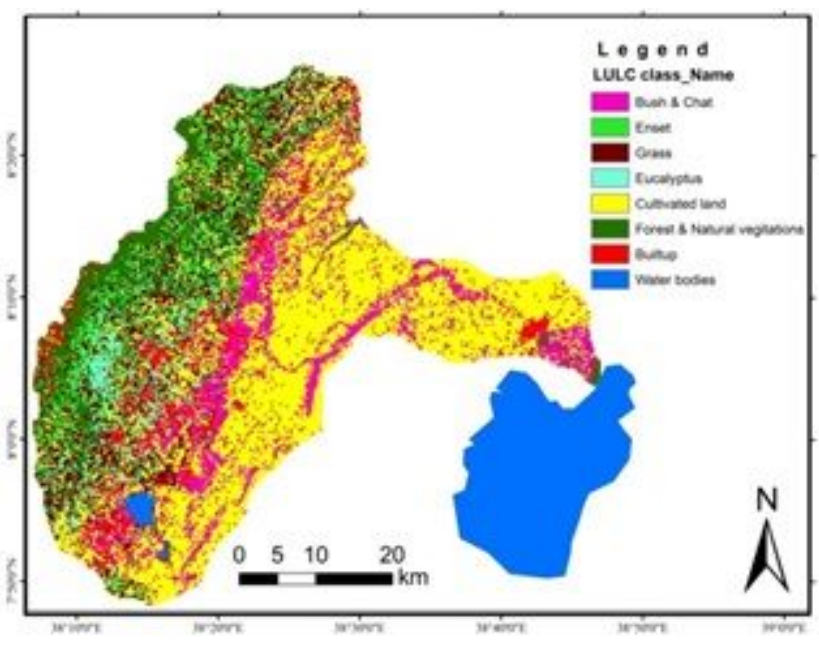

Figure 6

Land use system of the area for CN mapping 


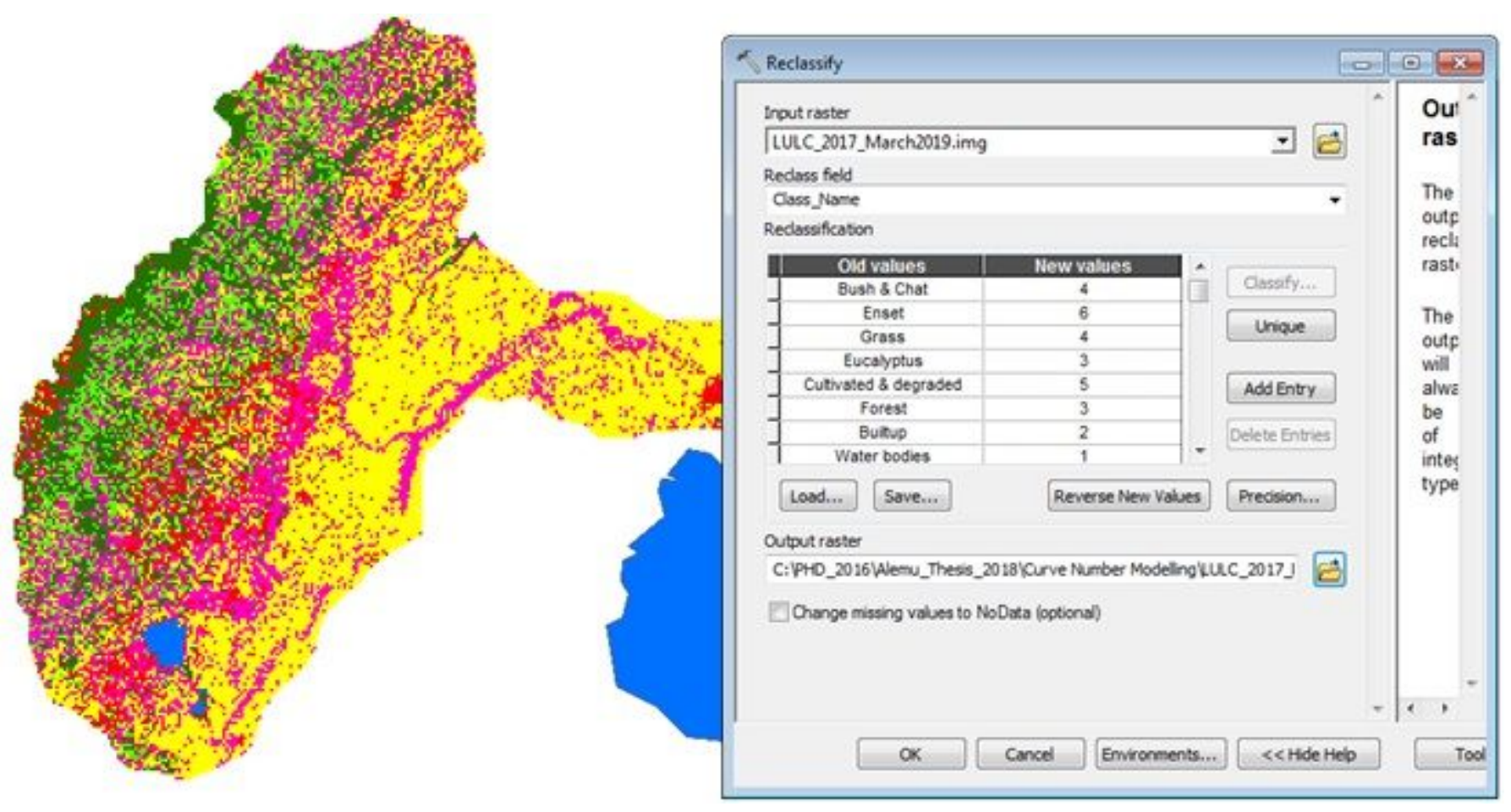

Figure 7

Reclassification window with assigned new values

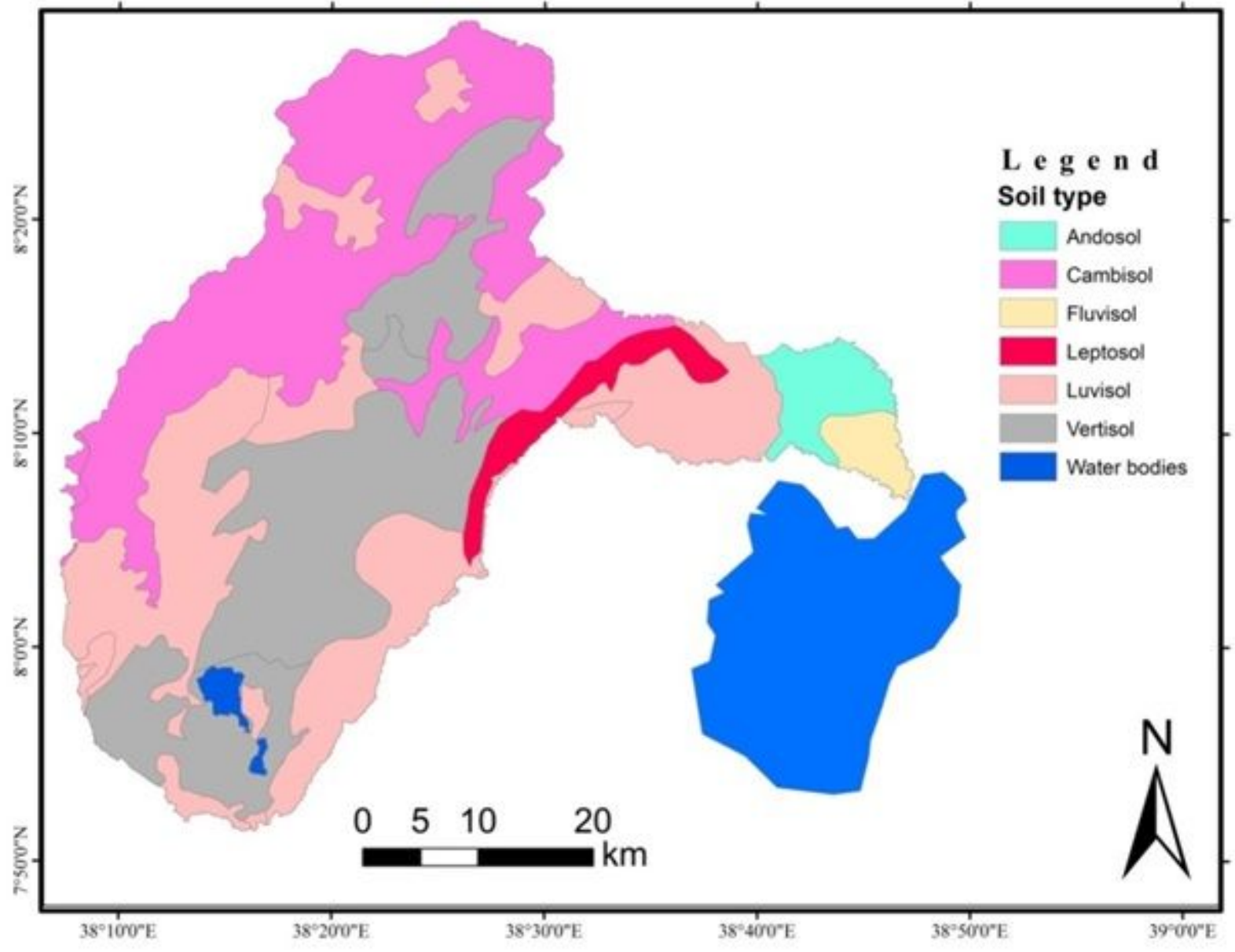

Figure 8 
Soil map of the area (MWIE, 2017)

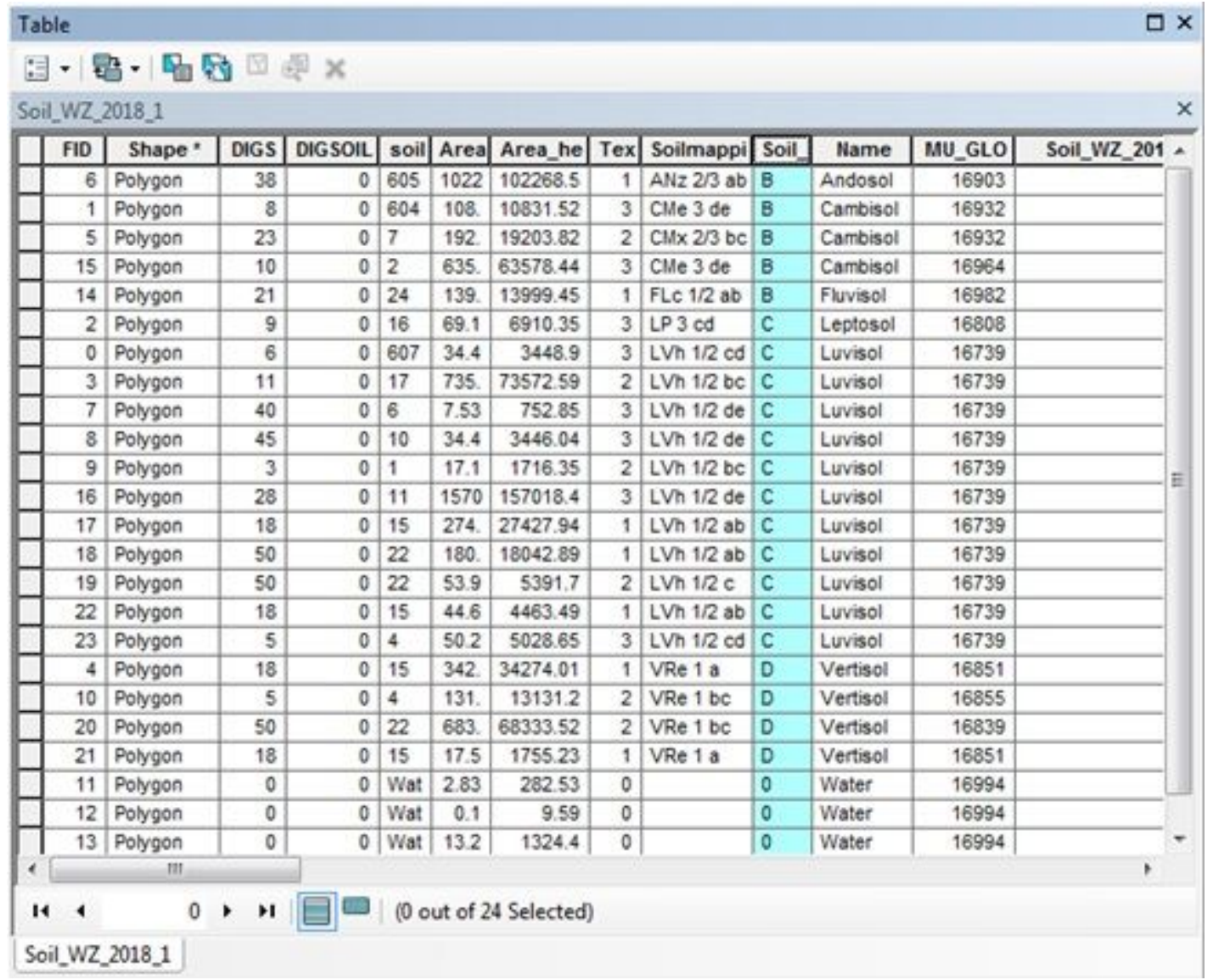

\section{Figure 9}

Hydrologic soil group (HSG) assignment

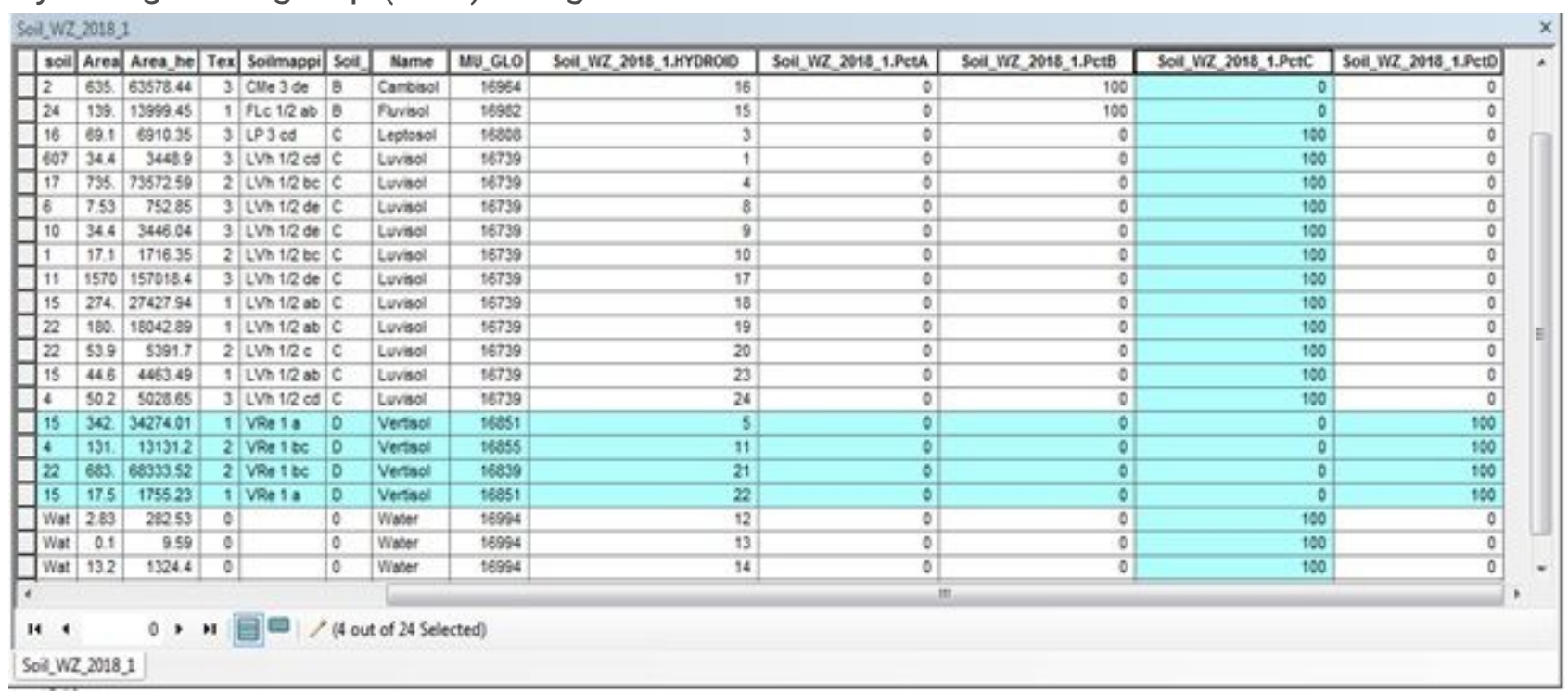

\section{Figure 10}

Standard curve number matrix assignment for different soil groups 


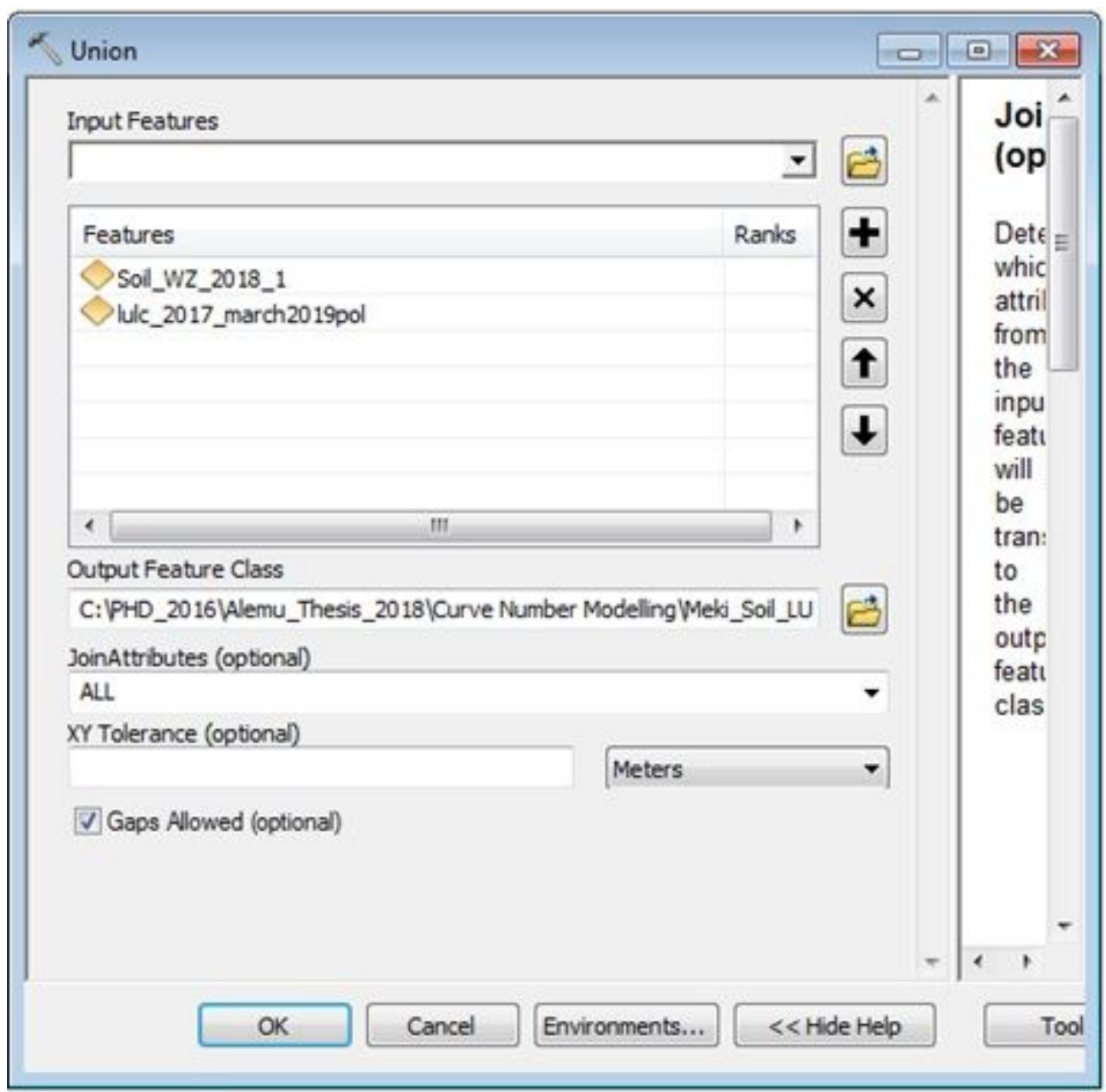

\section{Figure 11}

Soil land use union (Merge) of the watershed

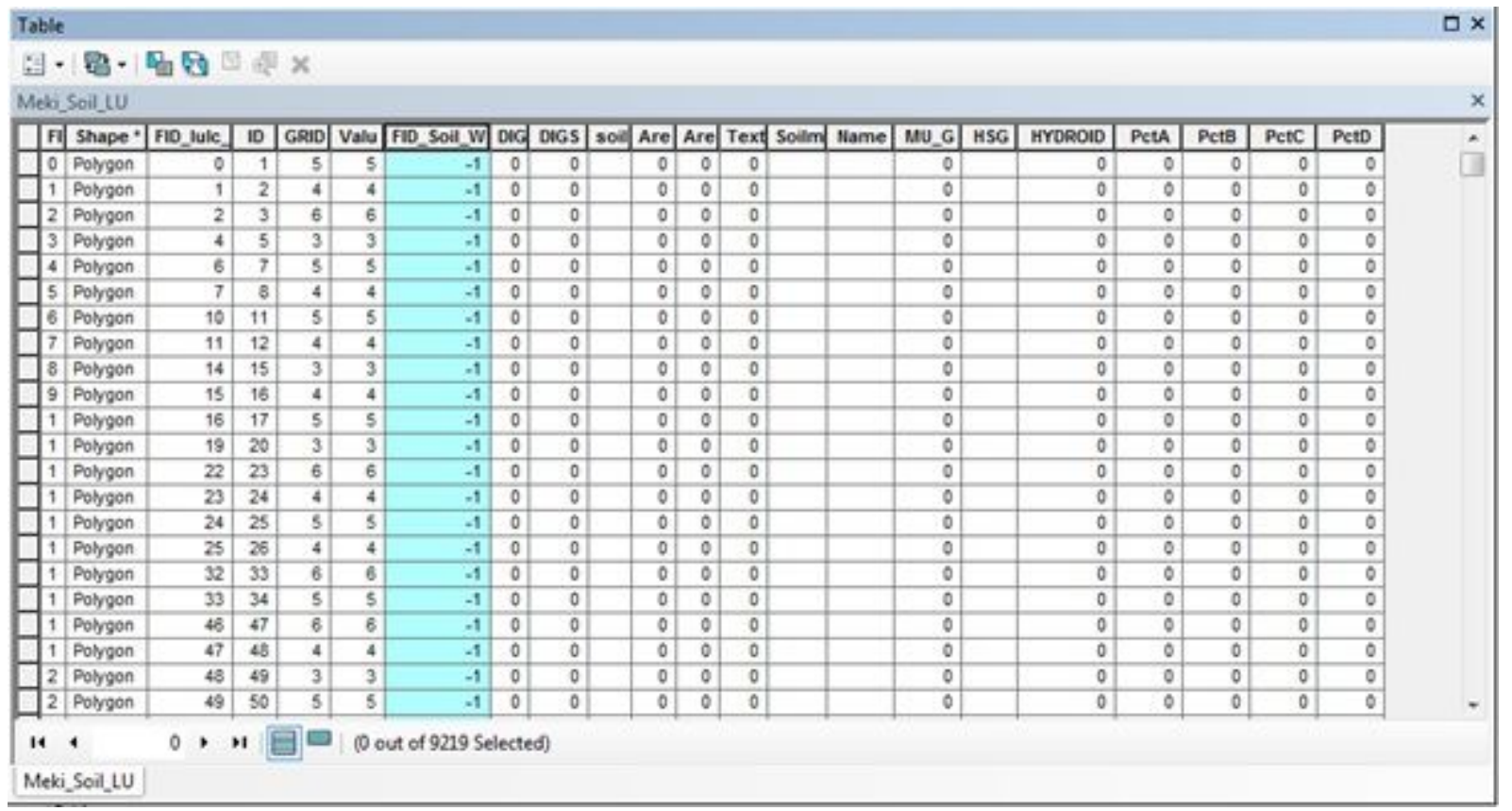

\section{Figure 12}


Avoiding sliver (-1) of the soil land use union of the watershed

\begin{tabular}{|c|c|c|c|c|c|c|c|c|c|}
\hline \multicolumn{5}{|c|}{ Table } & & & & & $\square \times$ \\
\hline \multicolumn{10}{|c|}{ : } \\
\hline \multicolumn{5}{|c|}{ cnlookup } & & & & & $x$ \\
\hline & Rowid & OBJEC & FIEL & LUVALUE & DESCRIPTION & A & $\mathrm{B}$ & $\mathrm{C}$ & D \\
\hline \multirow[t]{6}{*}{ 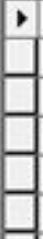 } & 1 & 0 & 0 & 1 & Water bodies & 100 & 100 & 100 & 100 \\
\hline & 3 & 0 & 0 & 2 & Builtup & 77 & 85 & 90 & 92 \\
\hline & 5 & 0 & 0 & 3 & Eucalyptus/Forest & 36 & 60 & 73 & 79 \\
\hline & 7 & 0 & 0 & 4 & Bush \& Chat/Grass & 49 & 69 & 79 & 84 \\
\hline & 9 & 0 & 0 & 5 & Cultivated \& degraded & 67 & 78 & 85 & 89 \\
\hline & 11 & 0 & 0 & 6 & Enset & 39 & 52 & 58 & 62 \\
\hline \multicolumn{10}{|c|}{$141, \cdots \mid$} \\
\hline \multicolumn{2}{|c|}{ cnlookup } & LULC_2 & $017 \_\wedge$ & March2019Re & ecl.img & & & & \\
\hline
\end{tabular}

\section{Figure 13}

Lookup table considering EBLUS

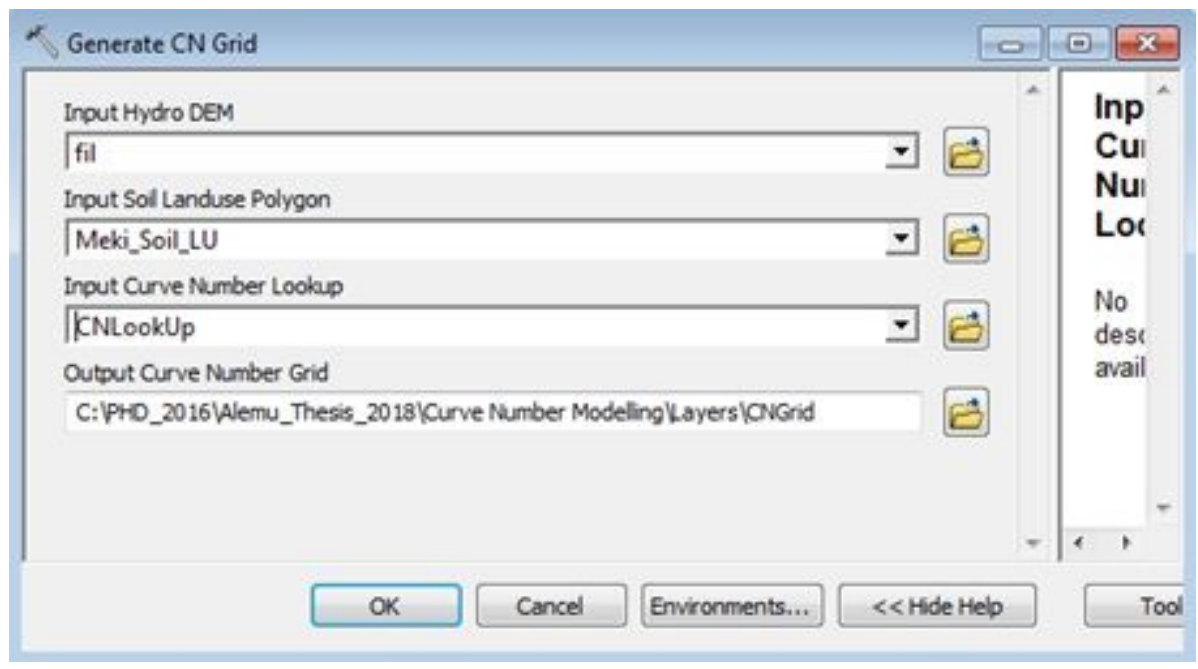

\section{Figure 14}

$\mathrm{CN}$ generation considering Enset-Based land use system 


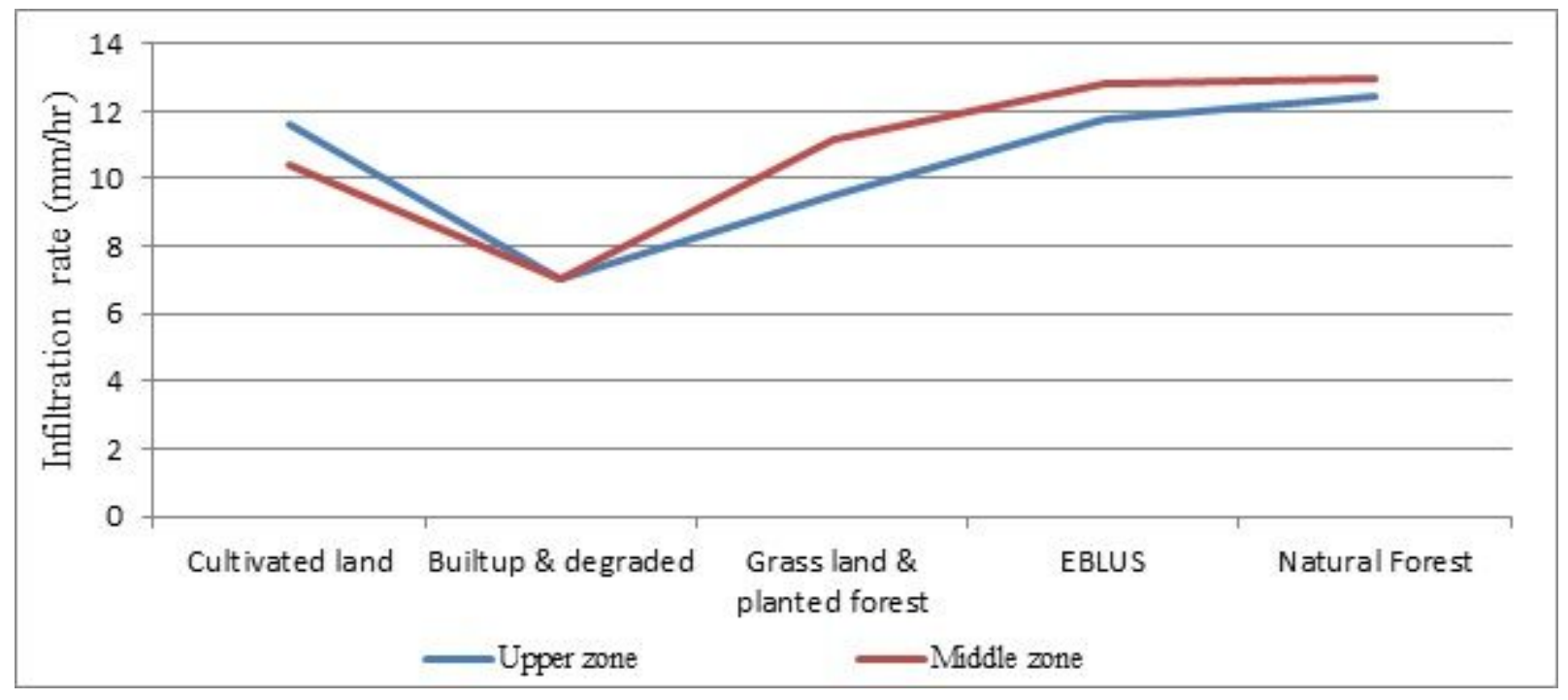

\section{Figure 15}

Vegetation zone based infiltration capacity of the soil $(\mathrm{mm} / \mathrm{hr})$

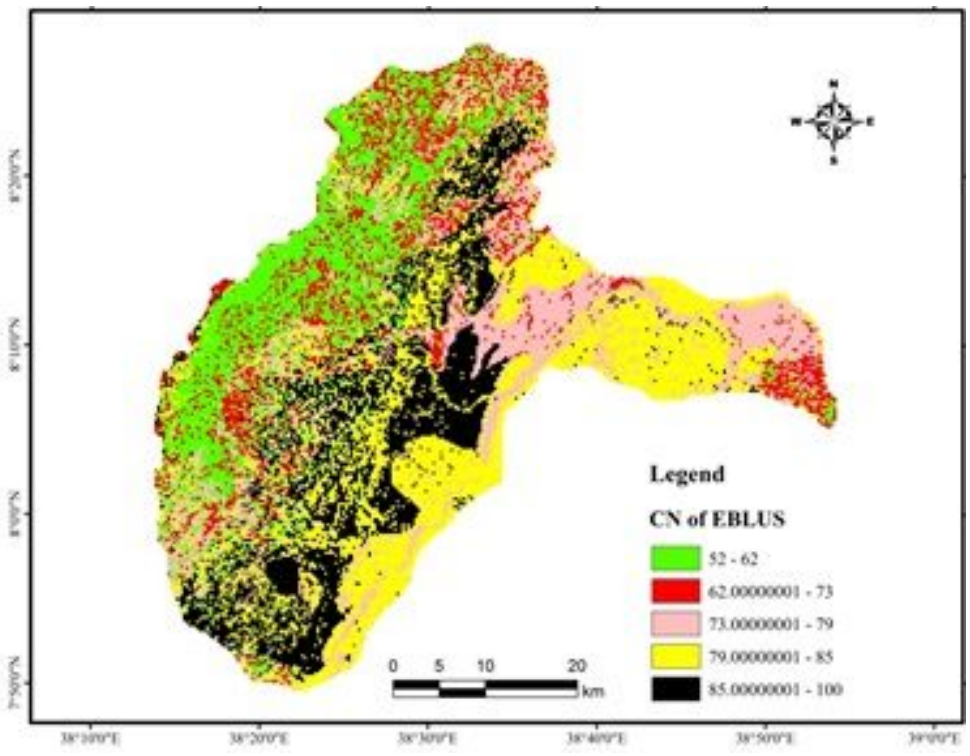

Figure 16

Average soil loss from sub-watersheds with respect to Rift valley limit 


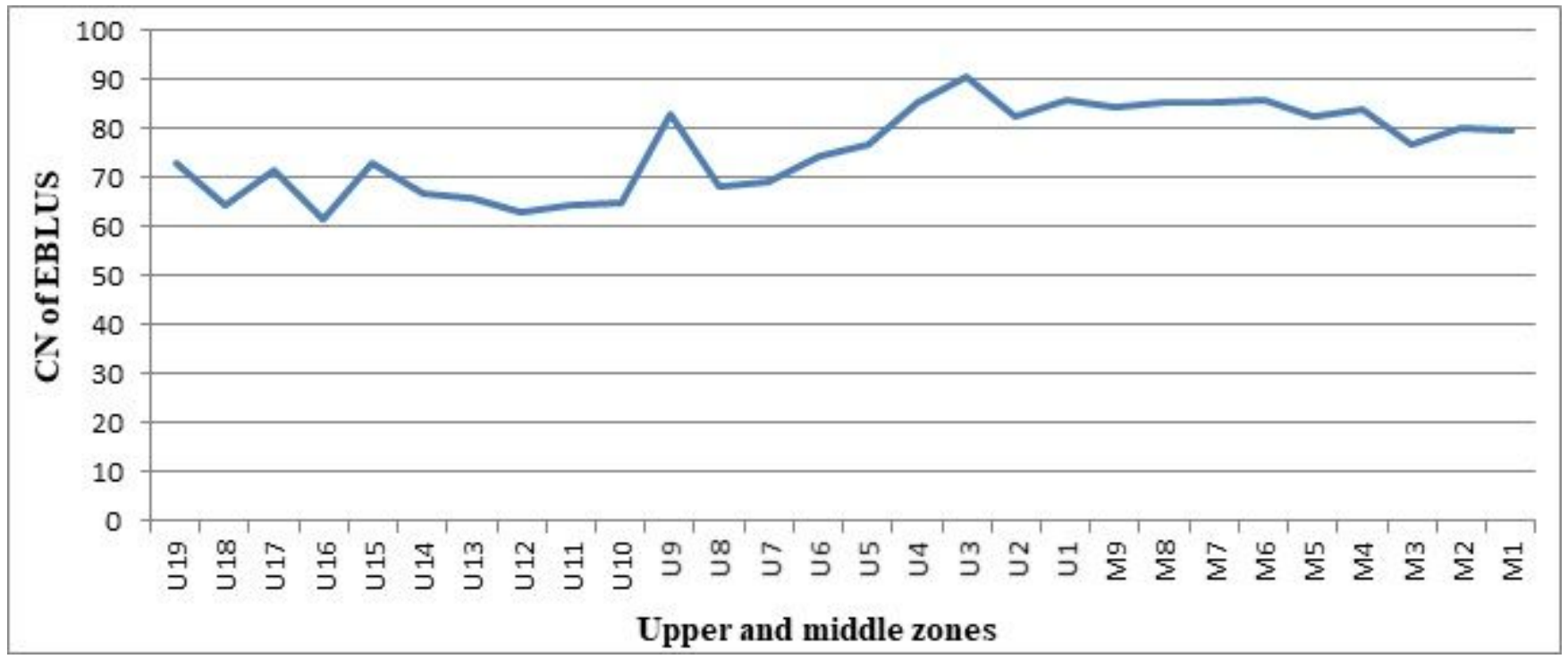

Figure 17

Curve number of EBLUS in the upper and middle zones

\section{Supplementary Files}

This is a list of supplementary files associated with this preprint. Click to download.

- Supplementary.docx 